Chapman University

Chapman University Digital Commons

Economics Faculty Articles and Research

Economics

9-2014

\title{
Cost Share Adjustment Processes for Cooperative Group Decisions about Shared Goods: A Design Approach
}

Edna T.Loehman

Purdue University

Richard Kiser

University of Arizona

Stephen Rassenti

Chapman University, rassenti@chapman.edu

Follow this and additional works at: http://digitalcommons.chapman.edu/economics_articles

Part of the Economic Theory Commons, Other Economics Commons, and the Public Economics Commons

\section{Recommended Citation}

Loehman, E. T., Kiser, R., \& Rassenti, S. J. (2013). Cost share adjustment processes for cooperative group decisions about shared goods: A design approach. Group Decision and Negotiation, 23(5), 1085-1126. doi: 10.1007/s10726-013-9342-x

This Article is brought to you for free and open access by the Economics at Chapman University Digital Commons. It has been accepted for inclusion in Economics Faculty Articles and Research by an authorized administrator of Chapman University Digital Commons. For more information, please contactlaughtin@chapman.edu. 


\section{Cost Share Adjustment Processes for Cooperative Group Decisions about Shared Goods: A Design Approach}

\section{Comments}

This is a pre-copy-editing, author-produced PDF of an article accepted for publication in Group Decision and Negotiation, volume 23, issue 5, in 2014 following peer review. The final publication is available at Springer via DOI: $10.1007 /$ s10726-013-9342-x.

\section{Copyright}

Springer 


\title{
Cost Share Adjustment Processes for Cooperative Group Decisions about Shared Goods: A Design Approach
}

\author{
Edna T. Loehman, Richard Kiser, and Stephen J. Rassenti*
}

For group decision about shared goods, the nature of the shared good and how its cost is to be shared among group members must be determined. Complexity arises from heterogeneity in preferences and endowments and nonlinear cost. To facilitate group decision, this paper proposes special type of group decision support system, a cost share adjustment process (CSAP), in which cost shares are adjusted iteratively via algorithmic rules until agreement is reached, ideally producing a socially optimal, cost feasible, and fair outcome. Design elements for CSAPs include message space, cost allocation and adjustment rules, controllers, and incentive rules, with many possibilities for a cost share adjustment process.

In contrast to public good literature, our designs apply for situations of nonlinear cost,with economies of scale and fixed costs. Because of impossibility theorems, a design approach is developed: simulation and economic experiment are employed to compare alternative designs. As simulation and experiment both indicate, complicated rules for incentive purposes may impede locating group agreement. Instead of complicated economic incentive rules, economic experiments show that unanimity Approval Voting can mitigate the effects of strategic behavior.

\subsection{Introduction}

\subsection{Definition of Shared Goods}

This paper concerns the design of a process for a cooperating group to find agreement about a shared good when there are benefits for the group to share its costs. With agreement, the shared good is jointly provided to the group, with each member of the group having potential access to it. The participants must agree simultaneously on the nature of the good to be provided and how its costs will be shared among group members.

Contemporary examples of shared goods are plentiful in both business and social contexts. A computer system is an example within a firm. Multiple divisions within the firm may have

\footnotetext{
*Respectively: Professor Emeritus, Department of Agricultural Economics, Purdue University, West Lafayette IN, loehman@ purdue.edu ; Principal Research Computing Specialist, Economic Science Laboratory, University of Arizona, Tucson, AZ, kiser@econlab.arizona.edu; Director, Economic Science Institute, Chapman University, San Diego CA, rassenti@ chapman.edu

This work was supported by NSF grant 9320937-SBR and NSF grant 9617788-SBR. Experiments were carried out at the Economic Science Laboratory, University of Arizona in 1996, 1997, 1998, 2000. Thanks to Eythan Weg, Lafayette, Indiana, for many useful discussions and encouragement along the way.
} 
different computing needs and budgets, but there may be some economies-such as for operations and maintenance -from having a common system. Once a computer system is provided, all divisions potentially have equal access to its utilization. Since needs and resources will differ by division, equal sharing of system costs among divisions may not be acceptable. Lack of agreement may lead management to impose a computer system which may be a poor fit for some.

A neighborhood recreational facility to be built in a commons is an example in a social context. The facility benefits the neighborhood if a common area can be used for recreation at lower maintenance and operation costs than individually, with a wider set of activities provided. Once built, recreation activities are available to all in the neighborhood. Heterogeneity is inherent: neighbors may differ in terms of recreational needs and income endowments as related to family characteristics and age, so that equal sharing of costs may be inappropriate. Lack of a method for finding agreement about cost sharing may mean that no facility would be provided.

Our goal is to determine methods for finding a shared good quantity and cost sharing so that all group members are better off than in a non-cooperative situation. Many potentially cooperative situations may result in no group action because of lack of a way to determine an acceptable outcome when preferences and endowments are heterogeneous. In such situations, employment of a group decision method could facilitate group agreement. By agreement is meant a situation such that all parties are better off than they would be in the "fallback" situation of no group provision, and the group decision should be voluntary.

This paper draws on economic literature for the design of cost sharing methods. Public goods are similar to shared goods in that the same good can be provided to a group of participants, although public goods usually involve a larger scale group size. Examples of public goods are public education, public libraries, and public radio and television. With a very large number of group participants, direct voluntary agreement about a public good and its finance is generally difficult. Therefore, decision about the nature of a public good is generally made through government, with finance accomplished through taxation.

In contrast to public goods, a shared good can have natural boundaries and a relatively small group size to limit congestion; these conditions may make participatory group decision and voluntary agreement more feasible than for public goods. Local public goods (Tiebout, 1956) similarly have well-delineated (geographic) jurisdictions. Different locales have different mixes of local public goods and taxes, and presented with the different combinations, potential residents choose the jurisdiction that best matches their preferences. There is no consideration of direct participation in determining the nature of local public goods in this literature.

Shared goods are also similar to club goods (Cornes and Sandler, 1960) in terms of having a limited group size. The main concern in club goods literature has been determining the optimal group size when there is congestion. However, homogeneity of group members has been the common assumption in club goods literature, making equal cost sharing appropriate.

The shared goods situation contrasts with cooperative game theory treatments as the 
Shapley value (Young, 1985), in which the nature of the good to be shared is already specified and for cost sharing, a formula could based on concepts of fairness and rationality as expressed in axioms. While fairness is obviously important in group decision, the concept of fairness may not be well-represented by axiomatic rules. Most important, the nature of a shared good is not generally pre-specified and is a primary matter for groups' decisions to share provision.

Loehman and Whinston (1971) suggested that public goods are a special case of jointly supplied public services that exhibit declining average costs. Because declining costs pose problems for finance through uniform pricing, a method of cost sharing through personalized cost shares - related to the Shapley value - was proposed. However, unlike game theory approaches, they recognized the problem of how to determine the level of the good. A bargaining process for finding agreement was proposed but was not detailed. We remedy this need here.

\subsection{Two Views on Public Goods}

Because of their similarities, views on public goods are relevant for shared goods. In 1954, Paul Samuelson characterized the impossibility of "decentralized spontaneous solution" for public goods; he said (p. 388, 1954): ...” no decentralized pricing system can serve to determine optimally these levels of collective consumption." Samuelson's conclusion was based on the hypothesis that the free-rider problem would destroy any voluntary provision of a public good. Much theoretical and experimental literature on incentive compatibility followed.

An alternative literature supports the possibility of voluntary provision of collective goods, which has implications for shared goods. Olson (1971, p.32) states that "Though there is a tendency for even the smallest groups to provide suboptimal amounts of a collective good..., the more important point to remember is that some sufficiently small groups can provide themselves with some amount of a collective good through the voluntary and rational action of one or more of their members." Thus, though acknowledging that members of a group inherently would prefer that others pay for a collective good, he believed that particularly for smaller groups, the existence of collective benefits greater than costs would promote group provision.

One historic example is early turnpikes. As Klein (1990) says: "The free-rider problem was overcome by an almost vigilant impulse to participate and to see that your neighbor did likewise..." Services provided by private communities are cases of shared goods, and private communities can use societal pressure to overcome free-riding (Foldvary, 1994).

In an experimental context, Smith $(1978,1979)$ demonstrated that free-riding need not be devastating for provision of public goods. In Smith (1976), an institution was defined to be a specified set of rules and procedures, and he found that outcomes are influenced by the nature of institutional rules. Self-interest and reciprocity are possible behaviors for any individual (Smith, 1997), and institutional rules can call forth either behavior. Smith (1989) also suggested a criterion for a successful institution that we adopt here: institutional rules should achieve a desirable outcome regardless of the mix of underlying individual behaviors. 


\subsection{Benefits of Group Agreement and Complexity as a Deterrent to Group Decision}

Situations in which collective action for shared goods is beneficial are likely to have nonlinear cost - such as economics of scale, fixed costs, or declining average costs - which must be covered. For fixed costs, the larger the sharing group, the lower is the share of fixed cost for each group member. When average unit costs decline as the scale of provision increases, there are individual benefits to be gained from participating in a group because cost per person in a group solution will be less than an non-cooperative (individual) solution.

Members of a sharing group often have heterogeneous preferences and different abilities to pay for a shared good. Perhaps because of complexity, equal cost sharing is frequently practiced. For example, there is equal sharing of a restaurant bill even when people have ordered meals with different costs. Natural solutions for cost sharing often use proportionality or equity rules (Young, 1994). The group problem is easily solved by equal shares if there is homogeneity of group members. Otherwise, the complexity of solving the group decision problem (Dasgupta,1997) may be an important deterrent to group provision and is a more constructive reason than freeriding to explain difficulties in group decision-making.

To illustrate complexity, we give an example that finding an optimal, cost feasible, individually rational solution can be computationally difficult when there is heterogeneity and nonlinear cost. Suppose preferences for three group members for a shared facility of size Q are as follows, where $\mathrm{x}_{\mathrm{i}}$ represents expenditure for all other goods and $\mathrm{M}_{\mathrm{i}}$ represents a budgetary limit for each group member denoted by "i":

$$
\begin{aligned}
& \mathrm{u}\left(\mathrm{x}_{1}, \mathrm{Q}\right)=\mathrm{x}_{1}+\gamma_{1} \log (1+\mathrm{Q}) \\
& \mathrm{u}\left(\mathrm{x}_{2}, \mathrm{Q}\right)=\mathrm{x}_{2}+\gamma_{2} \log (1+\mathrm{Q}) \\
& \mathrm{u}\left(\mathrm{x}_{3}, \mathrm{Q}\right)=\mathrm{x}_{3}+\gamma_{3} \log (1+\mathrm{Q})
\end{aligned}
$$

where $\Sigma \gamma_{\mathrm{i}}=131 / 8$. Suppose the cost of provision is $C(Q)=30+9 \mathrm{Q}+9 \mathrm{Q}^{2}$ and $\mathrm{x}_{\mathrm{i}}=\mathrm{M}_{\mathrm{i}}-\mathrm{S}_{\mathrm{i}}$ for cost shares $S_{i}$ summing to $C(Q)$. By maximizing the sum of utilities, the optimal good is $Q=1 / 24$. However, even with full information about preferences, determining the optimal quantity would be very difficult for a group without some sort of solver.

Besides the need for preference information and computational needs, a further difficulty arises in assigning cost shares. With quasi-linear utility functions as above when the optimal shared good level is independent of the distribution of income (Bergstrom and Cornes, 1983), determining an objective solution for cost shares is not possible by optimization.

\subsection{Concept of a Cost Share Adjustment Process and Background on Adjustment Processes}

Addressing complexity of the group decision problem for share goods, a group decision support system (GDSS) could help locate agreement about the nature of the good and cost sharing and thus could significantly improve group outcomes. We propose design of a special type of GDSS for the shared goods problem. A cost share adjustment process (CSAP) is an iterative 
process of decentralized message exchange with algorithmic equilibration to locate group agreement for a shared good. Cost shares and shared good quantity are adjusted via algorithm based on group member messages - until agreement about the shared good and its finance is reached. The specification of a cost share adjustment process involves defining a cost share instrument, together with adjustment rules for its parameters. The method allows for heterogeneity and nonlinear costs while requiring only limited information about preferences.

The design of CSAPs falls under the subject of mechanism design. Design of mechanisms or institutions to address allocation problems owes its beginning to Hurwicz (1973) with further development through the years (Hurwicz and Reiter, 2006), culminating in a Nobel Prize for Hurwicz in 2007. Two contributions of mechanism design literature are: impossibility theorems, the impossibility of finding a "perfect" mechanism for all environments once human strategic behavior is introduced (Hurwicz, 1972); and incentive compatible mechanisms that address strategic behavior in message generation (Mookherjee, 2008). Our design methods recognize impossibility theorems and incentive problems for shared goods, as explained below.

A less known branch of mechanism design is the concept of an adjustment process (Hurwicz, 1987). One idea of adjustment is that of the Walrasian auctioneer in a tatonnement ("groping") process; the auctioneer adjusts a market price until a supply-demand equilibrium is reached. Tatonnement has traditionally referred to price adjustment in a market process. ${ }^{1}$ The ability of price to equilibrate demand and supply in a market is well-known. Here we extend the idea of tatonnemont to adjustment of personalized prices in a share formula for a shared good.

Alternatively, Alfred Marshall (1920) saw a market process in terms of quantity adjustment: a market period starts with a given quantity, and quantity is adjusted if the supply price (what suppliers are willing to accept) is below the demand price (what buyers are willing to pay). Thus, two alternative forms of market adjustment are price and quantity adjustment, and these two adjustment methods also apply to shared goods, as we show here.

The context for a CSAP is planning in advance of carrying out a collective decision by a group. ${ }^{2}$ Malinvaud (1971) suggested that the role of the planner in decentralized message exchange is to substitute for direct message exchange among agents themselves. Decentralization concerns the designation of who has what information. In contrast to a "center" or "planner" having full information about a system, decentralization is favored because it reduces information costs and promotes privacy of information (Hurwicz, 1973). Termed the "invisible hand" by

\footnotetext{
${ }^{1}$ For tatonnement, no transactions are carried out until equilibrium is reached (Takayama, 1985, p.341).

${ }^{2}$ Tulkens (1978) differentiated between planning and voluntary exchange institutions: voluntary exchange is associated with market institutions and private consumption, while planning requires cooperation of citizens in an economy, with the planner acting in the best interests of the citizens. Here, both aspects apply: shared good decisions are voluntary but are made in a planning context.
} 
Adam Smith in a market setting, decentralization can result in an optimum solution without the need for centralized information about individual preferences. However, decentralization need not refer only to non-cooperative situations. While a decentralized process with private message exchange may appear non-cooperative, MAS-COLELL [1980] noted that decentralization is also relevant for cooperative situations to reduce information and transactions costs of agreement.

The role of message exchange and execution of the tatonnement adjustment process can be carried out by a networked computer system not requiring a human planner. At the same time, CSAP can be a substitute for direct negotiation. Direct negotiation may be difficult, with posturing and misrepresentation leading to group breakdown. The efficacy of computer-mediated communication (CMC) for group decision is supported by Li (2007) who compared CMC to faceto-face communication (FTF) for various functions of a group decision making process. Similar to other studies, she found that CMC groups (with 4 or 5 members) took a longer time than FTF to complete decision tasks. However, FTF did not have better group outcomes than CMC for the assigned tasks, because "social talk" had a negative impact on group effectiveness. Although her group decision tasks were relatively simple, CMC may also provide better outcomes than FTF communication for shared goods because of complexity.

We envision a CSAP to be a form of computer-mediated communication at the same time as providing algorithmic decision support. In the terminology of group decision support systems (Biro and Kovacs, 1994), the architecture for CSAPs is a multi-party communication protocol, with a central mediator (which can be a computer) who communicates directly with each group member without cross communication among the members. The notion of a distributed group decision support system - with decentralized information managed by a network system - has arisen because face-to-face communication is difficult for larger groups (Bui, 1987). Relatedly, Algorithmic Mechanism Design (Nisan and Ronen, 2001) in computer science literature combines ideas from economics and game theory with solution algorithms for online auction design.

\subsection{Contributions of this Paper}

Blumel et al. (1986, p.296) complained about the inconclusiveness of public good allocation mechanisms and attribute this to a lack of a comprehensive framework. Here, we provide such a comprehensive framework for shared goods, reaching from definition to computation and behavior.

The main contributions of this paper are: 1) proposing the concepts of shared goods and cost share adjustment process for decisions; 2) developing a mathematical economics (static and dynamic) foundation for CSAPs; 3) the design approach of identifying and comparing alternative cost sharing processes and adjustment procedures, here employing simulation and economic experiment. The design approach responds to impossibility theorems: there is no theoretically "best" method. In contrast to our design approach, many public good papers - both theory and experiment - have proposed and supported only one cost sharing or taxation method.

Our process idea combines aspects found in several literatures proposed in the 1960's: 1) 
decomposition, found in mathematical programming and decentralized planning $\left.{ }^{3} ; 2\right)$ iterative solution, found in organizational management theories ${ }^{4}$; and 3 ) use of controllers for coordination of engineering systems ${ }^{5}$. Decomposition refers to taking a complex overarching optimization problem and associating its solution with separate or decentralized solution for a set of simpler problems. With decentralization, each of the simpler problems is associated with its own small information set in place of a comprehensive information set for the overarching problem. Iteration with controllers reduces the complexity of optimizing. In a social system, it means involving cooperating parties in decision-making through coordination signals. These topics are still of interest for engineering control systems, ${ }^{6}$ and here we combine them in a novel way.

For design purposes, we develop a taxonomy for CSAPs based on the general theory of adjustment processes and coordination in engineering systems. Our taxonomy delineates message space, allocation rules, adjustment rules, and the nature of controllers as essential aspects of CSAPs. By varying these aspects, design of many CSAPs is possible. We identify share-taking and quantity-taking as two generic types, and share-taking is shown to have an important optimality property.

Messages between group members and a coordinator, which can be a computer, are the "stuff" of adjustment procedures. Following market paradigms, messages can include bids, quantities, or both. Bids are a natural language for small markets and auctions, while quantity demands are responsive to pricing. Size of the message space was a concern to early mechanism design literature for computational and information cost reasons (Reiter, 1974, Mount and Reiter, 1974), and a smaller size message space was deemed more desirable (Hurcwicz, 1994, 1973). Today, computer memory is not a prominent constraint. However, there may be a behavioral aspect of message space which we explore here with experimental economic methods.

Another contribution stems from our economic experiment design: a novel unanimity voting approach similar to natural group processing appears to ameliorate strategic behavior. We suggest that the voting approach is an alternative to complicated cost allocation rules found in incentive compatibility literature.

Our design of CSAPs draws on public goods theory, economic experiment, and theory of adjustment processes, each reviewed in sections of this paper. Section 2 gives historical background for public goods theory and experiments. A taxonomy for dynamic adjustment is developed in Section 3. Section 4 provides an economic theory foundation for CSAP design

\footnotetext{
${ }^{3}$ See Arrow and Hurwicz (1960) and Hurwicz (1970) for an economic resource allocation application. See Wong (1973) for an application of economic planning.

${ }^{4}$ Atkins (1974) used a mathematical programming framework for management control of budgets, investment, joint costs, etc. Cohen $(1980,1986)$ applied the iterative solution method to control in an organization, focusing on incentive problems of messaging.

${ }^{5}$ See Laub and Bailey(1978) for a two level hierarchical structure with coordinated communication for a general control problem.

${ }^{6}$ Chanron and Lewis (2005) study convergence in decentralized design for complex engineering systems.
} 
elements. Our main results are found in sections 5 through 8. In Section 5, we specify the general dynamic form for two types of CSAPs, share-taking and quantity-taking. In Section 6, we construct CSAPs based on cost allocation rules in economic literature and propose three new designs; we then use simulation to compare six CSAPs for convergence and optimality for a common environment. Section 7 describes experiment structure and comparison of share-taking and quantity-taking CSAPs, while Section 8 reports more extensive trials for one promising CSAP. Results support that a two-stage group process - proposal generation and unanimity voting for the final group decision - can frequently result in agreement that is near-optimal.

\subsection{A Brief History of Public Goods}

Because of relevance for our designs and experiments, we give a brief history of public goods in economic literature, including the desirability of voluntary agreement, incentive compatible mechanisms, adjustment processes, and experiments. Clearly, the volume of relevant work is large in scope. It has not received comprehensive treatment covering both theory and experiment. We highlight views about unanimity voting in theory and experiment.

\subsection{Definition of a Public Good}

Public goods literature addresses definition of a public good, optimal provision, and incentive compatible mechanisms to ameliorate free-riding. Samuelson (1954, p.387) defined a public good in terms of joint consumption: "a collective consumption good is one that all enjoy in common in the sense that each individual's consumption leads to no subtraction from any other individual's consumption." This has been commonly interpreted as "non-rivalry" in consumption, in contrast to "rivalry" for private goods. A "pure public good" has a zero marginal cost of adding additional participants once a good is provided (hence marginal cost pricing - as commonly prescribed - cannot be used); this marginal cost condition has limited applicability in real life.

In the literature, another defining characteristic is "non-excludability", i.e., it is not feasible to exclude use, once provided. Olson (1971, p.14) states that "a common, collective, or public good is any good such that if any person in a group consumes it, it cannot be feasibly withheld from others in the that group." Therefore, free-riding is inherent and difficult to prevent. Another aspect is indivisibility of benefits: it is not possible to assign fractional shares of the total benefit to individuals. Hart and Cowhey (1977) suggest that these various definitions overlap.

Joint supply (Head, 1962) - or joint provision, as used here - means that once produced, the good is available to more than one individual. Commenting on Samuelson's definition, Hart and Cowhey (1977) distinguish between "availability" and "use." For example, once provided a computer system in a firm will be available for all divisions, though it can be utilized differently among divisions. Similarly, a neighborhood recreation facility is available to all neighbors, but they would generally not use it equally. ${ }^{7}$

\footnotetext{
${ }^{7}$ The distinction between "availability" and "use" seems associated with the distinction between fixed (or equipment) costs and variable (or operating) costs. Whether or not joint provision occurs often hinges on how to finance fixed costs which may be relatively large. Fixed costs may not vary greatly over a range of users, so that once provided, the equipment is available to additional users. For example for a neighborhood playground, the basic
} 


\subsection{Voluntary Agreement and Unanimity}

Because of problems of free-riding and identifying beneficiaries, government provides public or collective goods and finances them through taxes. With public finance of collective goods, Wicksell (1986) recognized that coercion was inherent in government taxation: by separating decision and taxation, some people would be asked to pay for something they did not value in commensurate terms: "it would seem to be a blatant injustice if someone should be forced to contribute toward the costs of some activity which does not further his interest (p. 89). Wicksell - and later Lindahl and Olson - believed that it was possible and desirable to find voluntary agreement for such goods: "Provided the expenditure in question holds out any prospect at all of creating utility exceeding costs, it will always be theoretically possible, and approximately so in practice, to find a distribution of costs such that all parties regard the expenditure as beneficial and may therefore approve it unanimously" (Wicksell, 1896, p.89-90). Wicksell proposed the principle of unanimity to guarantee that all individuals would receive benefits commensurate to their cost share for a collective good. However, Wicksell recognized that if complete unanimity were required, collective action could be held hostage by strategic voting (Tideman, 1998). Therefore, the "Voluntary Exchange Theorists" such as Lindahl and Wicksell proposed that governments should establish tax shares and expenditures as if they were responding to negotiations among individuals (Musgrave, 1939 in Dougherty, 2003).

\subsection{Optimality and Why it is not Achieved}

Samuelson (1954) was the first to define optimality clearly for public goods, deriving the necessary condition for optimality in terms of "marginal valuations" (here, called "marginal bids"), now considered to be the foundation of the modern theory of public goods (Pickhardt, 2006). Samuelson's optimality condition given in Section 3 also applies directly to shared goods.

To satisfy this optimality condition requires determining marginal valuations for participants for the public good, and Samuelson (1954) suggested that participants would underreveal their marginal valuations. Thus the impossibility of a market or decentralized solution: "it is in the self-interest of each person to give false signals" about their preferences for the public good and to "snatch some selfish benefits in a way not possible under the self-policing competitive pricing of private goods" (p.388-89). The resulting incentive compatibility literature focused on enticing participants to correctly reveal these valuations or bids.

Olson (1971) explained free-riding in another way: because of the property of nonexcludability, there is an incentive to withhold contribution, hoping that others' contributions will be sufficient. However, Olson had a broader view recognizing the possibility of collective provision for labor and business unions and other nonmarket groups. He believed that a collective good could be provided by a small group when there is benefit from collective action, though its provision may be suboptimal.

equipment may be the same whether the number of users is small or large. At the same time, variable costs reflect the number of users, such as for playground monitors for the neighborhood playground. Covering operating costs is less problematic than covering fixed costs. For example, many goods and services now provided by government have "user charges" to cover variable costs. 
Lindahl first offered a solution concept for public goods (Roberts, 1974). Lindahl (1919) considered the situation of two parties trying to determine a public activity and sharing the tax bill. He diagrammatically showed that there could be a point of voluntary agreement and suggested that his concept of equilibrium tax shares could be extended to more parties.

\subsection{Historical Adjustment Processes}

Adjustment processes specify how an equilibrium can be found through a dynamic system. Prominent examples are summarized below. Except for experiments for the SDC process, these processes have not been operationalized either computationally or experimentally. Several papers (Roberts, 1974; Tulkens, 1977; Blumel et al., 1986; Chander, 1993) have reviewed adjustment processes proposed in the literature and found various weaknesses in each method. ${ }^{8}$

\subsubsection{Lindahl Process}

Lindahl (1919, translated in Musgrave and Peacock 1958) was the first economist to detail a process for reaching agreement for a public good. The Lindahl equilibrium (described below) the desired outcome of the process - has been considered a definitive solution concept by economists.

The Lindahl process as described in Silvestre (2003) is as follows. A set of cost shares is proposed; if the corresponding level of public good for this expenditure is desirable for all parties, then the outcome is accepted. Otherwise, if any party desires an increase in the public good, their share is increased; the public good is set at the minimum of the public good proposals for the set of shares, and the tax shares are specified according to the differences in public good demands. The process stops when there is unanimity in the level of public expenditure. The nature of the process guarantees that participant benefits will increase as the public good increases, but the outcome may be sub-optimal (Roberts, 1974).

\subsubsection{MDP Process}

Instead of being tax-price guided, the MDP Process, independently suggested by Malinvaud (1971) and Dreze and De La Vallee Poussin (1971) is quantity-guided (Blumel, Pethig, and von dem Hagen, 1986). Using the terminology in this paper to describe this method: starting from a feasible state, the coordinator proposes the total level of public good to be supplied. Each participant then reports her marginal valuation to obtain an increase from this level. The coordinator then computes the increase in the public good by comparing the total of bids to marginal cost for the increase and uses an allocation rule to determine the tax distribution for funding the public good. The distribution of cost is such that benefits for participants are increasing as long as the public good level is changing. The process stops when the total marginal valuations and marginal cost are equal, thus satisfying optimality.

\footnotetext{
${ }^{8} \mathrm{We}$ are reminded of the impossibility results of Hurwicz: that no mechanism will be fully incentive compatible and optimal at the same time.
} 
Chander (1993) proposed a process in which participants propose their bids to increase the public good, which is determined similar to MDP. Here, the tax-price per unit of public good for each participant is defined endogenously to be a share of cost as determined by her bid relative to the total of bids. Any equilibrium corresponds to a ratio equilibrium (Kaneko, 1977). We use a similar sharing rule for the Optimal Bid Process described in Section 6.

\subsubsection{Sequential Direct Contribution Process}

Bagnoli et al. (1989, 1991, 1992) proposed a sequential process - Sequential Direct Contribution (SDC) - for an environment with discrete public good levels. Incremental bids relative to incremental cost determine the shared good level increase: the good level is sequentially increased by one level, starting from zero, as long as the sum of incremental bids covers the incremental cost of a change. The process stops when incremental costs are no longer covered by the sum of incremental bids by members. If the sum of bids exceeds costs, Bagnoli et al. (1992) argued that any excess should not be returned for incentive reasons.

Their stopping rule is termed a "Provision Point" rule and was proposed as an incentive against free-riding: the public good level provided will be sub-optimal if participants under-bid. By the voluntary nature of bidding, all group members will be better off at the terminal step compared to the initial condition without the public good. The bid instrument was shown to lead to a Nash equilibrium that is Pareto optimal (Bagnoli and Lipman, 1989), and their theoretical result has been supported by experiments (Bagnoli and McKee, 1991).

\subsection{Incentive Compatibility}

Incentive compatibility mechanisms have been proposed to address free-riding, typically in the form of a tax or penalty function. The protocol of theory is to show that a Nash equilibrium satisfies optimality. Two prominent examples aim at achieving a theoretical Lindahl equilibrium.

Groves-Ledyard. The Groves-Ledyard (GL) mechanism uses a cost allocation formula with a penalty function for deviation from the group demand for the public good. For the GL mechanism, an incremental quantity for the public good is proposed by each group member, and the total quantity to be provided is the sum of the proposed increments. As an incentive for truthful demand revelation, whether a participant proposes a high or low quantity, they are penalized according to the difference relative to the group average. The form of the penalty function is constructed so that cost feasibility is achieved. Cost is linear homogeneous, so that there is a direct relation between proposed total quantity and provision cost.

In theory, a Nash equilibrium with the Groves-Ledyard mechanism is Pareto optimal. However, it is recognized that feasibility for the individual budget constraint and individual rationality may not be satisfied at a Groves-Ledyard equilibrium (Greenberg et al., 1977; Groves and Ledyard, 1987).

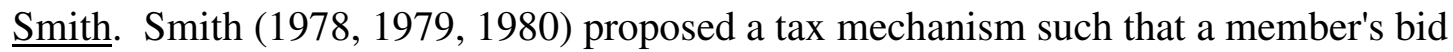
message would not directly influence her own price; thus a false valuation message would have no affect on a person's cost share. The process used both bid and quantity messages to determine the public good and cost share for a linear homogeneous cost function. A person's price was 
constructed from the difference between marginal cost and the average bid per unit excluding that person. For linear cost, bids are adjusted so that the sum of bids will cover cost exactly.

\subsection{Public Good Experiments 9}

Public good experiments have generally used a small size group to test behavior under a variety of conditions and are therefore relevant for shared goods. The focus of experiments has been to examine the effects of free-riding on group outcomes, as related to experimental conditions. Experiments have most often used repeated bidding; however this repetition is not algorithmic. Most experiments used the unrealistic case of linear homogeneous cost (not allowing economies of scale or fixed costs). Several studies tested unanimity voting rules and found them to improve group outcomes. To assess the desirability of experimental outcomes, measures of "efficiency" have compared experimental outcomes regarding bids, quantities, or net benefits to a theoretical optimum. Experimental conditions and results are summarized here for later comparison to our experimental results.

\subsubsection{Voluntary Contribution Mechanism}

The Voluntary Contribution Mechanism (VCM) has been the predominant experimental method for testing free-riding behavior for public goods (Isaac, Walker, and Thomas, 1984; Isaac, McCue, and Plott, 1985; Isaac, Schmitz, and Walter, 1989); results are reviewed for later comparison to our results. VCM uses bid messages to determine public good provision, with cost shares determined directly from bids. A common finding is that as a bidding mechanism is repeated, bids decay, resulting in less and less public good provision.

Coates and Gronberg $(2001,1996)$ tested the effects of sequential versus simultaneous bidding in VCM for groups of size four. Sequential bidding provides more information about others' bids than simultaneous bidding, when others' contributions are not known at the time a bid is made. Efficiency was measured as the percent of maximum group surplus (a measure of net benefit) achieved. The sequential institution achieved 65-69\% efficiency whereas the simultaneous institution achieved $44-50 \%$, depending on the level of provision cost.

Sell and Wilson (1991) tested how information about previous contributions affects current contributions for VCM. Alternatives were no information, information about average group contribution, and information about individual contributions. They found that more information about individual contributions improved contributions, achieving at best around $70 \%$ of the optimum contribution after nine repetitions of VCM. Aggregate bid information achieved only about $50 \%$ of the optimum contribution, with about the same result for no information.

Chan et al. $(1999,1996)$ tested the effects of heterogeneity on contributions in a VCM game. Three-person groups were used. In their experimental design, in contrast to many VCM experiments, the optimum contribution is not the full endowment. With face-to-face communication and heterogeneity in endowment and reward, about $70 \%$ of the optimum contribution was made, and about $60 \%$ of the optimum was obtained with no communication.

\footnotetext{
${ }^{9} \mathrm{~A}$ recent more complete review of public goods experimental literature is given in Chen (2008).
} 


\subsubsection{Groves-Ledyard Mechanism}

Chen and Plott (1996) tested the Groves-Ledyard mechanism with two levels for the punishment parameter. They used linear homogeneous cost and quadratic utility functions. In their experimental procedure - named Periodic Process - each round had independent bidding and outcomes; the number of repetitions was fixed at thirty. There were four experiments of two sessions each with 5 subjects. They found that with a higher punishment parameter, a higher level of the public good is provided, and efficiency (percent of the optimal public good level) is higher. Average efficiency for a low punishment parameter was $91.1 \%$ and $97.7 \%$ for a high parameter.

\subsubsection{Smith's Experiments}

Smith $(1978,1979,1980)$ experimentally tested alternative institutional rules for group decision about public goods. Smith's Auction Mechanism and Free-rider Mechanism differed in terms of message space and rules that determine the public good level and cost shares. Smith's Auction Mechanism used both bid and quantity messages; for incentive purposes, an individual's bid did not influence her tax or cost share. The bid message was the proposed contribution for the public good, and the quantity message was the proposed quantity for the public good. The resulting good level was the average of group quantity proposals. The Free-rider Mechanism uses bidding similar to the Voluntary Contribution Mechanism in that there was no incentive mechanism for bidding. The Free-rider Mechanism determined quantity directly from the sum of bids because, for linear homogeneous cost, cost is proportional to shared good quantity.

Both Auction and Free-rider mechanisms were embedded in a voting game. Each repetition resulted in proposed cost share and shared good quantity. Messaging was repeated until group members unanimously agreed to end the process at a particular cost allocation and shared good quantity. The terminal step determined the final cost shares and quantity.

Comparisons were based on a small number of trials for each institution. For 1979 results: with a group size of six persons with eight to ten trials, the Auction mechanism required an average of 8.3 rounds to find agreement; the Free Rider Mechanism required fewer iterations: 5.75 rounds on the average. For the Auction Mechanism, the public good quantity was $73 \%$ of the theoretical optimum (calculated from Table 5 of Smith, 1979); near optimal results were obtained for games with agreements, but $20 \%$ of the games ended in no agreement. The Free-rider Mechanism also achieved an average public good level of $73 \%$ of the optimum, with agreement in all games. Smith (1979) - seeming surprised - concludes in the Summary section that 1) his incentivized Auction Mechanism did not produce larger quantities of the public good than the Free-Rider Mechanism; 2) his Free-Rider Mechanism did not result in typical free-riding. He attributes this to the unanimity voting requirement.

\subsubsection{Other Mechanisms}

Harstad and Marrese (1982) developed the Seriatim process using repeated bidding, but rather than being terminated by a vote, the process is terminated when all players repeat their previous bid messages. They tested the Groves-Ledyard mechanism with quadratic utilities and linear homogeneous cost in nine experiments with 31 subjects. The number of bidding cycles ranged from 3 to 38; the average number of iterations was 15.4. The average efficiency was $94 \%$. 
Banks et al. (1988) tested Smith and VCM rules with and without a unanimity requirement. Their unanimity rule is similar to Smith's: each round members vote whether or not to stop the process; if they all vote no, the process is repeated up to five times. If they all vote yes, then payoffs are made according to the results of the final round. They found the Smith process with voting to be more efficient than VCM. They also found that the unanimity voting rule reduces the efficiency of the outcome, but that the unanimity rule prevented the decay in performance that could otherwise occur with VCM. Six games with ten subjects were used for each institution.

\subsection{Dynamic Foundation: Adjustment Processes and Application to CSAPs}

Mathematical description for the dynamic structure of CSAPs is developed here by applying the general structure of adjustment processes and coordination methods to CSAPs. The resulting taxonomy for CSAPs is based on message space, allocation rules, adjustment rules, and controllers; these components can be varied to produce alternative CSAPs. Mathematical notation follows that of the original authors.

\subsection{Message Adjustment Process}

Hurwicz (1960) formalized the idea of a message adjustment process for resource allocation problems. Formally, the environment for a process $(e)$ is a vector of environments $e^{i}$ for each agent, including preferences and technologies. Agents iteratively present messages that belong to a message space $M$. Agents $i$ send messages $m^{i}$ to each other according to individual response functions $f^{j}$ given the message vector $m$ :

$$
\mathrm{m}^{\mathrm{i}}(\mathrm{t}+1)=\mathrm{f}^{\mathrm{i}}(\mathrm{m}(\mathrm{t}), \mathrm{e})
$$

An adjustment mechanism is said to be private if each agent's message is determined solely on the basis of individual characteristics $e^{i}$. Suppose the message process has a stationary message $m *(e)$. The group outcome is then determined by an allocation rule $h$ :

$$
\mathrm{z}=\mathrm{h}\left(\mathrm{m}^{*}(\mathrm{e})\right)
$$

Thus, an adjustment process is defined by an ordered triple $\langle M, f, h\rangle$. A process is evaluated according to whether its equilibrium lies in the pre-specified desirable set $F(e)$.

Jordan $(1987,1995)$ extended Hurwicz's concept by describing message exchange in the form of differential equations, allowing theorems about stability of dynamic systems to be applied. Further, Jordan described agents' messages as being controllers. Denoting the state of the system by a vector $s$, controllers are determined by behavioral rules given the state and environment: $c^{i}=f^{i}\left(s, e^{i}\right)$, and adjustment of the state is defined by an adjustment function $\alpha$ : $\dot{s}=\alpha(c, s)$. Jordan studied the stability of the equilibrium of the resulting system:

$$
\dot{\mathrm{s}}=\alpha\left(\left\{\mathrm{f}^{\mathrm{i}}\left(\mathrm{s}, \mathrm{e}^{\mathrm{i}}\right)\right\}, \mathrm{s}\right)=\mathrm{F}(\mathrm{s}, \mathrm{e})
$$

\subsection{Engineering Systems Theory of Coordination and Controllers}

To address complex group decision problems, Reiter (1995) described a coordination process as being a set of procedures to solve a joint optimization problem that consists of: "(i) an 
algorithm for computing a function, the decision rule, and (ii) an assignment to individual agents of the steps required to execute the algorithm." Consistent with this description, a CSAP is a coordination process specifically designed to solve the group shared good optimization problem.

From engineering systems theory, coordination is a method of producing a solution to a control problem through a decomposed, multi-level form in which a coordinator orchestrates the independent activities of local decision agents through coordination parameters called controllers (Findeisen et al., 1980, p.84). There is an overall goal for an interconnected system with local decision units. The coordinator has the aim to coordinate local decision units to achieve this goal through the coordination parameters (Findeisen et al., 1980, p.12). Controllers may be systemwide or localized. A local controller is a coordination parameter for a local decision unit. The coordinator uses feedback functions or adjustment rules for controllers to stabilize the system.

Findeisen et al. (p.1) provide several reasons for coordination: 1) the decision-making capability of an individual unit is limited; 2) subsystems may have limited communication with one another; 3 ) there is a cost and/or a distortion in transmitting information. These reasons also apply to CSAPs, and below we give examples of alternative processes with different controllers.

\subsection{A Taxonomy for CSAPs}

We combine Hurwicz's and Jordan's descriptions with engineering systems theory to describe a general algorithmic adjustment process that applies for CSAPs.

An algorithmic adjustment process is described by $\prec M, f, c, s, \alpha, h \succ$ where: $M$ denotes the message space; $f$ is the set of behavioral response functions; $c$ is a vector of controllers; $s$ are variables describing the system state; $\alpha$ denotes the algorithmic adjustment rule for the controllers; $h$ is the allocation rule that links outcome variables to the system state. Controllers $c$ affect individual behavior and are designed to equilibrate the system. For local controllers, each agent receives a personalized control message $c^{i}$ and submits a message to the coordinator in accord with system information and behavior rules.

The form of an algorithmic adjustment process is:

$$
\begin{gathered}
\mathrm{m}^{\mathrm{i}}=\mathrm{f}^{\mathrm{i}}(\mathrm{m}, \mathrm{c}, \mathrm{s}, \mathrm{e}) \\
\dot{\mathrm{c}}=\alpha(\mathrm{m}, \mathrm{s}), \\
\dot{\mathrm{s}}=\mathrm{h}(\mathrm{m}, \mathrm{s}), \\
\mathrm{c}(0)=\mathrm{c}^{0}, \mathrm{~s}(0)=\mathrm{s}^{\mathrm{o}}
\end{gathered}
$$

The dynamic equilibrium of this game has a stationary message vector $m^{*}(e)$ for $\dot{s}=0, \dot{c}=0$. An algorithmic adjustment process can be viewed as a differential game between participants and the coordinator, each controlling a subset of system variables ${ }^{10}$. The game stops when there is a dynamic equilibrium.

The coordinator applies the algorithmic adjustment rule $\alpha$ to controllers based on messages and the existing state. The change in the state of the system is determined from

\footnotetext{
${ }^{10}$ Arrow and Hurwicz (1977) proposed formulating resource allocation as a differential game. (1977). Dore (1979) - for a multi-product firm - suggests the need for incentives for the coordinator.
} 
messages and the existing state. State variables include variables that are system-wide (for example, the level of the public good) as well as those that pertain individuals such as the level of utility, payoff, or net reward.

A taxonomy for CSAPs results from this general description; a CSAP is characterized by:

1) the message space: bids and/or quantity messages from group members; proposed cost shares and proposed group quantity by the coordinator;

2) the cost allocation rule;

3 ) its controllers (here, personalized prices and/or group quantity $Q$ );

4) its adjustment rules: how controllers are modified in response to messages.

\subsection{Criteria for Message Adjustment Processes}

Criteria for adjustment processes include both information needs and convergence properties. Regarding information: 1) following Hurwicz, an adjustment process is privacypreserving if $c^{i}$ is a local controller, and each player has only aggregated information about other players (examples of aggregation are the average of quantities demanded and the sum of others' bids); 2) following Reiter, a process is information-conserving if adjustment rules require only information about the previous state, not information about all previous states. Thus, less information is needed to control the system when the process is information-conserving.

Convergence and stability are important mathematical criteria for dynamic adjustment processes (Jordan, 1987, 1995; Mas-Colell, 1986). Desirable properties are that: (i) for any initial state, the corresponding path should converge to some solution of the stationary equation system (system stability); ii) given an equilibrium outcome, if the initial state is perturbed from the equilibrium, the process should converge to a point in the neighborhood of the equilibrium (local stability) (Mas-Colell, Whinston, and Green, 1995; pp. 621-622). Additionally, Laub and Bailey (1978) suggested two criteria for a coordination process: the dynamic process should converge to an equilibrium, and the equilibrium should solve the decision problem.

\subsection{Static Economic Foundation for CSAPs}

Economic theory provides the foundation for specifying allocation and adjustment rules for CSAPs. The basic concepts and notation are developed in this section. In a later section, adjustment rules for price/quantity controllers are specified corresponding to two types of CSAPs, share-taking and quantity-taking, based on this section.

First described is the desired nature of an equilibrium of an adjustment process. Next the message space and controllers are specified in terms of prices and/or quantities. We also delineate why the Lindahl equilibrium and Voluntary Contribution Mechanism are not appropriate.

The setting and notation are as follows. A group is engaged in making a voluntary decision about the quantity and cost shares for a shared good. Suppose there are only two goods to be considered: the shared good $(Q)$ and a private good $(x)$ representing all other goods, and assume that each group member $(i)$ desires a positive amount of the shared good. Preference 
orderings for each group member over the two goods are represented by utility functions $u^{i}$, and members have endowments $M_{i}$. The cost function for the shared good relative to the private good is $C(Q)$, and we assume increasing marginal cost, $C(0)=0$, and declining marginal utility for $Q$.

\subsection{Cost Share System}

The foundation for share-taking is a cost share system. A cost share system and the notion of a cost share equilibrium (CSE) were proposed by Mas-Colell and Silvestre (1989, 1991, 1994); their characterization allowed general cost functions and feasible $Q$. A cost share system has personalized cost share schedules $T_{i}(Q)$ for each group member, such that $T_{i}(0)=0$ and $\Sigma T_{i}(Q)=$ $C(Q)$ for any $Q$. The cost share equilibrium (CSE) is a feasible $Q^{*}$ such that no group member would prefer a different shared good level for the given cost share system, thus satisfying

$$
\mathrm{u}^{\mathrm{i}}\left(\mathrm{x}_{\mathrm{i}}{ }^{*}, \mathrm{Q}^{*}\right) \geq \mathrm{u}^{\mathrm{i}}\left(\mathrm{M}_{\mathrm{i}}-\mathrm{T}_{\mathrm{i}}(\mathrm{Q}), \mathrm{Q}\right)
$$

for all members i and private goods $x_{i}^{*}=M_{i}-T_{i}\left(Q^{*}\right)$. That is, a CSE has unanimity shared good $Q^{*}$ for cost shares corresponding to $T_{i}\left(Q^{*}\right)$ and is a Pareto optimum: no other feasible shared good level is preferred by all group members for the given set of cost allocation schedules.

Mas-Colell and Silvestre (1989) showed that the CSE is in the core, thus is individual- and group- rational and showed that a CSE can be mapped into a Lindahl equilibrium, thus proving its existence. However, description of the CSE does not indicate how it is to be located, which is the purpose of dynamic adjustment for CSAPs.

\subsection{Pareto Optimality, Share-taking, and Cost Share Equilibrium}

Pareto optimality - often represented as maximizing the sum of utilities subject to a feasibility constraint - is the keystone concept for welfare economic theory. Rather than being an actual goal of calculation, maximizing the sum of utilities is used here as a construct for institutional design of a pricing instrument: any pricing tool that does not maximize this sum could be improved on without making anyone worse off.

For the shared good $Q$, a Pareto optimum is the solution of:

$$
\begin{aligned}
& \underset{\mathrm{x}_{\mathrm{i}}, \mathrm{Q}}{\operatorname{Max}} \sum \mathrm{u}^{\mathrm{i}}\left(\mathrm{x}_{\mathrm{i}}, \mathrm{Q}\right) \\
& \text { s.t. } \sum \mathrm{x}_{\mathrm{i}}+\mathrm{C}(\mathrm{Q}) \leq \sum \mathrm{M}_{\mathrm{i}} \\
& \mathrm{x}_{\mathrm{i}}, \mathrm{Q}_{\mathrm{i}} \geq 0
\end{aligned}
$$

Any interior optimum must satisfy the Samuelson (1954) condition (a necessary condition for optimality) that the sum of "marginal valuations" - marginal utility of the public good relative to marginal utility of the private good at $Q$ - is equal to marginal cost of additional $Q^{11}$ :

\footnotetext{
${ }^{11}$ Second order conditions are used to ensure existence of an optimum. In general there may be multiple equilibria with any pricing instrument.
} 


$$
\sum_{i} \frac{u_{Q}^{i}}{u_{x}^{i}}=C^{\prime}(Q)
$$

The paradigm for market design is to define a pricing instrument that produces an equilibrium that achieves a Pareto optimum, and the appropriate pricing instrument for market goods is uniform pricing. Similarly, for public goods, we use cost shares with personalized prices to achieve an equilibrium that is Pareto optimum. For general cost functions, the use of a cost share system $\left\{T_{i}(Q)\right\}$ allows the Pareto optimality problem to be decentralized, and for nonlinear cost, it provides for a more general solution concept than the Lindahl equilibrium (see below).

Share-taking behavior means that each group member takes her cost share schedule $T_{i}\left(Q_{i}\right)$ as given and then determines her shared good proposal $Q_{i}$ to maximize her utility. The quantity by group member $(i)$ for the shared good is the solution of:

$$
\begin{gathered}
\operatorname{Max}_{x_{i}, Q_{i}} u^{i}\left(x_{i}, Q_{i}\right) \\
\text { s.t. } x_{i}+T_{i}\left(Q_{i}\right) \leq M_{i} \\
x_{i}, Q_{i} \geq 0
\end{gathered}
$$

For share-taking behavior, each group member's proposed quantity equates their marginal valuation to their marginal cost share:

$$
\frac{\mathrm{u}_{\mathrm{Q}}^{\mathrm{i}}}{\mathrm{u}_{\mathrm{x}}^{\mathrm{i}}}=\mathrm{T}_{\mathrm{i}}^{\prime}\left(\mathrm{Q}_{\mathrm{i}}\right)
$$

The cost share equilibrium - achieved when these conditions are simultaneously satisfied at unanimous quantity $Q^{*}$ - satisfies the Samuelson condition by definition of the cost share system. Furthermore, by definition of the cost share system, the cost of the shared good is exactly covered.

\subsection{Linear Cost Share Equilibrium and Personalized Prices}

Mas-Colell and Silvestre (1989) defined a linear cost share equilibrium (LCSE) as a special form of CSE. For this type of equilibrium, the cost share instrument has a specific form specified in terms of cost share parameters $s_{i}$ and personalized prices $p_{i}$ :

$$
\mathrm{T}_{\mathrm{i}}(\mathrm{Q})=\mathrm{s}_{\mathrm{i}} \mathrm{C}(\mathrm{Q})+\mathrm{p}_{\mathrm{i}} \mathrm{Q} \text {. }
$$

As they showed, a LCSE is Pareto optimal if the sum of shares $s_{i}$ equals one and the sum of prices $p_{i}$ equals zero. Figure 1 illustrates the LCSE for a group with two members. Since prices should sum to zero, one person's price is positive while the other's is negative. That is, starting from equal shares and two group members, one person's share will be more than an equal share while the other's is less than an equal share.

\subsection{Lindahl Equilibrium is not Optimal with Nonlinear Cost}

For public goods, the Lindahl equilibrium with personalized prices $p_{i}$ has been the most prominent solution concept; here we show it does not work with non-linear cost. The Lindahl 
equilirium can be viewed as a special case of LCSE with zero cost share parameters.

For the Lindahl equilibrium, given her personalized price, each participant determines a public good proposal $Q_{i}$ maximizing her utility subject to her budget constraint:

$$
\begin{gathered}
\operatorname{Max}_{x_{i}, Q_{i}} u^{i}\left(x_{i}, Q_{i}\right) \\
\text { s.t. } x_{i}+p_{i} Q_{i} \leq M_{i} \\
x_{i}, Q_{i} \geq 0
\end{gathered}
$$

Thereby, a participant's quantity proposal $Q_{i}$ sets her marginal valuation equal to her price:

$$
\frac{u_{Q}^{i}}{u_{x}^{i}}=p_{i}
$$

Equilibrium requires unanimity $Q_{i}=Q^{*}$ with prices satisfying $\sum p_{i}=C^{\prime}\left(Q^{*}\right)$. Thus, any equilibrium satisfies the Samuelson condition. For nonlinear cost, there is a problem with the Lindahl solution because the total tax collection exceeds cost when marginal costs are increasing:

$$
\sum_{i} p_{i} Q^{*}=C^{\prime}\left(Q^{*}\right) Q^{*}>C\left(Q^{*}\right)
$$

That is, any equilibrium will not actually be Pareto optimal, because the excess funds could be redistributed to make at least some group members better off.

\subsection{Marginal Bids}

Bid messaging is relevant for both share-taking and quantity-taking processes. To describe bidding, we first define willingness to pay (WTP) for the shared good at a given Q to be the most that a person would pay for an incremental increase of $q$ in $Q$. For person $i$, $W T P^{i}$ WTP equalizes utility before and after the change (a compensating variation, in the terminology of welfare economics):

$$
u^{i}\left(M_{i}-T_{i}(Q)-W T P{ }^{i}, Q+q\right)=u^{i}\left(M_{i}-T_{i}(Q), Q\right)
$$

it can be implicitly determined from the above to be a function of $Q$ and incremental change $q$.

The marginal willingness to pay $\left(\operatorname{MWTP}^{i}(Q)\right)$ for person $i$ is how much - at given a level of $Q$ - that a person would be willing to pay for a marginal increase in the level of $Q$. Marginal willingness to pay is the derivative of $W T P^{i}$ with respect to quantity. By the Implicit Function Theorem applied to the above equation, marginal willingness to pay is equal to Samuelson's marginal valuation:

$$
\operatorname{MWTP}^{i}(Q)=\frac{u_{Q}^{i}}{u_{x}^{i}}
$$

evaluated at $Q$ and $x_{i}=M_{i}-T_{i}(Q)$. For CSAPs, we use the notation $b_{i}$ to denote the marginal willingness to pay - here termed the marginal bid. For a marginal bid: a proposed shared good 
quantity is taken as given, and bids are made in order to obtain a marginal increase in Q.

\subsection{Personalized Pricing at a LCSE}

From above, at a LCSE each group member's marginal bid should equal to the marginal charge at the equilibrium quantity $Q^{*}$ :

$$
\operatorname{MWTP}^{\mathrm{i}}\left(\mathrm{Q}^{*}\right)=\mathrm{s}_{\mathrm{i}} \mathrm{C}^{\prime}\left(\mathrm{Q}^{*}\right)+\mathrm{p}_{\mathrm{i}}
$$

We will use this result to define adjustment rules below for personalized prices for CSAPs. Rewriting the equilibrium condition for a LCSE,

$$
\mathrm{p}_{\mathrm{i}}=\mathrm{MWTP}^{1}\left(\mathrm{Q}^{*}\right)-\mathrm{s}_{\mathbf{i}} \mathrm{C}^{\prime}\left(\mathrm{Q}^{*}\right) \text {. }
$$

That is, at equilibrium personalized prices $p_{i}$ should be the differences between the marginal bid and the share of marginal cost. This relation is the basis for adjustment rules below.

\subsection{Fairness of a Linear Cost Share Equilibrium}

A fairness condition for a LCSE with a linear cost share system can be obtained from the above price definition when there are equal share parameters $s_{i}=1 / n$ for group size $n$. Then, the difference in equilibrium personalized prices for any two group members is equal to the difference in their marginal willingness to pay:

$$
\mathrm{p}_{\mathbf{j}}-\mathrm{p}_{\mathbf{i}}=\operatorname{MWTP}^{\mathrm{j}}\left(\mathrm{Q}^{*}\right)-\mathrm{MWTP}^{\mathrm{i}}\left(\mathrm{Q}^{*}\right)
$$

i.e., a member with a higher willingness to pay than others will receive a larger personalized price.

Theorem: For a LCSE with equal share parameters $s_{i}=1 / n$, the personalized price satisfies the fairness condition that it is the difference between a person's marginal willingness to pay and the average marginal willingness to pay. Thus, $M W T P_{i}$ greater than average will result in a positive personalized price (more than an equal share) and for reverse case will result in a negative price (less than an equal share).

Proof: For a LCSE, the sum of personalized prices should be zero. Summing over group members in the above relationship, the result is obtained.

\subsection{Non-optimality of the Voluntary Contribution Mechanism}

The Voluntary Contribution Mechanism has been prominent in economic theory as well as experiment (Bergstrom, Blume, and Varian, 1986). Here, the Voluntary Contribution Mechanism (VCM) is shown not to result in a Pareto optimum, hence is not a good institution for a CSAP.

The Voluntary Contribution Mechanism uses bid messages regarding voluntary contributions $B_{i}$. Provided others' bids are known; the sum of others' bids $\Sigma_{j \neq i} B_{j}$ is taken as given when an individual determines her bid $B_{i}$. For feasibility, the public good quantity is determined such that the sum of bids equals or exceeds the cost for this quantity. For continuous $Q$ and cost $C(Q)$, the Nash equilibrium bid $B_{i}$ for each participant simultaneously solves the following optimization problem for nonnegative bids and private consumption $x_{i}$ (Varian,1994): 


$$
\begin{aligned}
& \operatorname{Max}_{x_{i}, Q, B_{i}}{ }^{i}\left(x_{i}, Q\right) \\
& \text { s.t. } x_{i}+B_{i} \leq M_{i} \\
& B_{i}+\sum_{j \neq i} B_{j} \geq C(Q) .
\end{aligned}
$$

For each group member, first order conditions for an interior equilibrium are:

$$
\frac{u_{Q}^{i}\left(M_{i}-B_{i}, C^{-1}\left(\sum_{j} B_{j}\right)\right)}{u_{x}^{i}\left(M_{i}-B_{i}, C^{-1}\left(\sum_{j} B_{j}\right)\right)}=C^{\prime}\left(C^{-1}\left(\sum_{j} B_{j}\right)\right) .
$$

The set of equilibrium conditions does not satisfy the Samuelson condition for optimality. As Dasgupta (1997, p. 191) suggested, the non-optimality of the Nash solution could lead to difficulties in supplying public goods with VCM. Also, determining a Nash equilibrium for VCM can be as difficult as finding a Pareto optimum (Laffont,1988); in particular, Moore et al. (1997) showed that existence of a Nash equilibrium is problematic when there are fixed costs.

\subsection{Two Generic CSAP Types: Share-taking and Quantity-taking}

Here, we formally describe share-taking and quantity-taking as two distinct types of dynamic adjustment processes. Results in this section link static and dynamic theories in Sections 3 and 4: a share-taking process results in a theoretical optimum by its use of a cost share system. In contrast, a quantity-taking process - based on bidding - is not necessarily optimal.

\subsection{General Form for Share-taking Processes}

For a share-taking process, group members take individual cost share schedules $T_{i}(Q)$ as given and respond with messages about their quantity demands. For a linear cost share instrument, personalized prices are local control parameters, and the group aggregate quantity proposal is also a control parameter. The general form for a share-taking CSAP is as follows:

1. Given the personal cost share schedule $T_{i}(Q)$, each member states her proposal $Q_{i}$.

2. The coordinator determines the group plan $\bar{Q}$ by aggregating proposals $Q_{i}$.

3. The coordinator computes control parameters and new cost share schedules based on the member messages and the adjustment rule. ${ }^{12}$

The process repeats until the same quantity is proposed by all members: $Q_{i}=\bar{Q}$.

The distinguishing characteristic of a share-taking process is that it is built on adjustment of a cost share system. Therefore we have the following result:

\footnotetext{
${ }^{12}$ For the Bid/Quantity Process described in Section 6, group members also propose marginal bids which
} are used to determine personalized prices. A Provision Point test determines the aggregate $\bar{Q}$ together with quantity proposals, as described in Section 7. 
Theorem: Assuming truthful messages, and increasing utility and cost functions, a dynamic equilibrium for a share-taking CSAP is a Pareto optimum.

Proof: The proof is immediate: any dynamic equilibrium achieves a cost share equilibrium, and based on the result of MCS (1989), any cost share equilibrium is optimal.

\subsection{General Form for Quantity-taking Processes}

For quantity-taking, members take the suggested group quantity as given and respond with bids to increase this group quantity. The suggested group quantity is the control parameter. A quantity-taking process starts from an initial feasible quantity level, which can be zero:

1. The coordinator proposes a group quantity $\bar{Q}$.

2. Given $\bar{Q}$, group members present bids to increase this level.

3. Given bids, the coordinator determines a change in $\bar{Q}$ and cost shares.

The process continues until a stopping rule is engaged.

Unlike share-taking processes, any equilibrium is not necessarily Pareto optimal, and cost may not be exactly covered. For an example, see the following simulated MDP process. Later, we present the Optimal Bidding Process that in theory achieves a special case of cost share equilibrium and so is optimal.

\subsection{Comparison of Alternative Cost Share Adjustment Processes}

In this section, we describe and compare alternative CSAPs. We show that many of the cost allocation suggestions in the literature result in convergence and/or optimality failures. (Further numerical examples of iterative processes can be found in Section 7 with messaging from experiments and Appendix 2 with "truthful" messaging.)

Three processes are from the literature. MDP (Malinvaud,1971; Dreze and De La Vallee Poussin, 1971) is a quantity-taking process using bid messages; it was originally specified as an adjustment process. Groves-Ledyard $(1977,1980)$ used only quantity messages, while Smith's $(1978,1979,1980)$ cost allocation rules used bids and quantities. ${ }^{13}$ Because Samuelson identified misrepresentation in bidding as the culprit for impossibility of designing decentralized mechanisms for public goods, Smith's focus was on creating an incentive rule for bidding, whereas the Groves-Ledyard incentive rule was based on a penalty function built on quantity messages. In effect, their specifications provide alternative cost allocation rules. To form CSAPs from their cost allocation rules, we add price adjustment rules. ${ }^{14}$

\footnotetext{
${ }^{13}$ Because linear cost directly relates bids to quantities, the "bid only" message space was possible.

${ }^{14}$ As originally specified, no adjustment procedures were included by Smith and Groves-Ledyard. Instead, their experiments used repetition of messaging, relying on experimental subjects to find a common good quantity.
} 
We propose three new CSAPs, each with a different message space, based on the cost share equilibrium and price/quantity controllers. Two share-taking CSAPs are based directly on the linear cost share instrument with price controllers. The Quantity Process uses only quantity messages, while the Bid-Quantity Process uses both bids and quantities. A new quantity-taking process using only bid messages has the theoretical property of optimality - in contrast to VCM because it produces a ratio equilibrium (Kaneko, 1977), a special case of LCSE with zero personalized prices.

Thus, possibilities for message space are: both bid and quantity messages; only bid messages, and only quantity messages. Demonstrating myriad possibilities, Table 1 compares taxonomically these six alternative CSAPs in terms of control parameters, the form of cost information, message space, and incentive rules.

Design criteria are needed to compare alternative designs. Criteria found in the literature relate to both theory and behavior: 1) achievement of Pareto optimality; 2) cost feasibility; 3) convergence of the adjustment process; 4) fairness; and 5) success in locating an acceptable (individually rational) group outcome. Speed of convergence is a measure of transactions costs. In Table 2, the relative success of these six CSAPs is compared in these terms through simulation with truthful messaging.

\subsection{MDP Planning Process}

The MDP planning process was fully specified as an adjustment process. In brief, given a proposed quantity $\mathrm{Q}$ to be supplied, each member sends the coordinator a marginal bid message $b_{i}$. The coordinator then determines shared good quantity according to an adjustment rule: quantity is increased if the sum of marginal bids covers marginal cost, and decreased otherwise. For feasibility, the process must start from an initial tax collection that covers cost.

Adjustment rules for quantity and personalized tax shares $\tau_{i}$ as originally specified are:

$$
\begin{aligned}
& \dot{\mathrm{Q}}=\gamma\left[\sum \mathrm{b}_{\mathrm{i}}-\mathrm{C}^{\prime}(\mathrm{Q})\right] ; \\
& \dot{\tau}_{\mathrm{i}}=\mathrm{b}_{\mathrm{i}} \dot{\mathrm{Q}}-\mathrm{s}_{\mathrm{i}} / \gamma \dot{\mathrm{Q}}^{2} ; \\
& \dot{\mathrm{x}}_{\mathrm{i}}=-\dot{\tau}_{\mathrm{i}} .
\end{aligned}
$$

$s_{i}$ are distributional parameters that sum to one and $\gamma$ is a speed of adjustment parameter that must be specified. At the dynamic equilibrium, cost shares are defined by the cumulation (integral) over personalized tax increments over all iterations. ${ }^{15}$ At a dynamic equilibrium, the Samuelson condition is satisfied and taxes are stationary. The cost allocation for each member is the total charge at the terminal level, which is the sum or integral of the tax increments starting from the initial charge. The personalized tax increments over members cumulated over iterations satisfies:

$$
\Sigma_{\mathrm{i}} \int \dot{\tau}_{\mathrm{i}} \mathrm{dt}=\int \dot{\mathrm{Q}} \mathrm{C}^{\prime}(\mathrm{Q}) \mathrm{dt}=\mathrm{C}(\mathrm{Q})+\mathrm{K}
$$

where $\mathrm{K}$ is the constant of integration. If cost is linear homogeneous, $\mathrm{K}$ would be zero, so cost

\footnotetext{
${ }^{15}$ Roberts (1974) pointed out that to correct for income effects, incremental taxes must be subtracted from income at each step as the bidding process proceeds.
} 
would be exactly covered by the tax cumulation. However, with a fixed cost, cost, cost may not be exactly covered. If excess revenue is collected, the situation would not be Pareto optimal, since all members could be made better off with refunds.

The novelty of the MDP process is that by construction, the tax increments are designed so that each step is utility-improving, providing incentives for cooperation:

$$
\begin{gathered}
\Delta u^{i}=u_{x}{ }^{i}\left(\dot{x}_{i}\right)+u_{Q}{ }^{i}(\dot{Q}) \\
=\left(u_{x}{ }^{i} s_{i} / \gamma\right)(\dot{Q})^{2} \\
\geq 0 .
\end{gathered}
$$

therefore by individual rationality, group members should agree to a group equilibrium outcome.

\subsection{Modifying the Groves-Ledyard Mechanism to form a CSAP}

The Groves and Ledyard $(1977,1980)$ method used only quantity messaging, which translated directly to cost because of assumed linearity. To result in a LCSE, the cost share instrument should be of the form $T_{i}(Q)=s_{i} C(Q)+p_{i} Q$. To construct a CSAP, we first modify the GL allocation rule to accommodate nonlinear cost and add an adjustment rule. The modified G-L cost share instrument is:

$$
\mathrm{T}_{\mathrm{i}}(\mathrm{Q})=\mathrm{s}_{\mathrm{i}} \mathrm{C}(\mathrm{Q})+\gamma / 2\left[(\mathrm{n}-1) / \mathrm{n}\left(\mathrm{Q}-\mathrm{Q}_{-\mathrm{i}}\right)^{2}-\mathrm{V}_{\mathrm{i}}^{2}\right]
$$

where $Q_{-i}=1 /(n-1) \sum_{j \neq i} Q_{j}$ is the mean public good without member $i$, and $V_{i}^{2}=1 /[2(n-1)(n$ 2)] $\sum_{h \neq i} \sum_{k \neq i}\left(Q_{h}-Q_{k}\right)^{2}$ is a variance term that produces a personalized tax. The term in brackets times the penalty parameter is a personalized tax. The sum over $i$ of the personalized taxes is zero by construction, so that cost share allocations sum to total cost. Both high and low demanders are penalized for deviation from the group average. The punishment parameter $\gamma$ is arbitrary. As Chen and Plott (1996) show, larger values of $\gamma$ force faster agreement.

The cost share form above suggests the adjustment rule for personalized prices:

$$
\mathrm{p}_{\mathrm{i}}^{\mathrm{t}+1}=\gamma / 2\left[(\mathrm{n}-1) / \mathrm{n}\left(\mathrm{Q}_{\mathrm{i}}^{\mathrm{t}}-\mathrm{Q}_{-\mathrm{i}}^{\mathrm{t}}\right)^{2}-\left(\mathrm{V}_{\mathrm{i}}^{\mathrm{t}}\right)^{2}\right] / \overline{\mathrm{Q}}^{\mathrm{t}}
$$

Average quantity demanded $\bar{Q}, Q_{-i}$, and $V_{i}$ are taken from the previous round. By definition, the personalized prices sum to zero each round, so that any equilibrium is a LCSE.

\subsection{Modifying the Smith Rule to form a CSAP}

Smith's rule determined the individual's cost share from others' bid messages to avoid the effects of bid misrepresentation. We first modify Smith's cost allocation rule to be in the form of a cost share system for nonlinear cost:

$$
\mathrm{T}_{\mathrm{i}}(\mathrm{Q})=\mathrm{s}_{\mathrm{i}} \mathrm{C}(\mathrm{Q})+\left[\left(1-\mathrm{s}_{\mathrm{i}}\right) \mathrm{C}^{\prime}\left(\mathrm{Q}_{-\mathrm{i}}\right)-\sum_{\mathrm{j} \neq \mathrm{i}} \mathrm{b}_{\mathrm{j}}\right] \mathrm{Q}
$$

where $b_{j}$ denotes the marginal bid to increase $Q$ by one unit, $\Sigma_{j-i}$ denotes the sum over $j$ excluding member $i$, and $Q_{-i}$ denotes the group average proposal excluding member $i$. At an equilibrium, $Q_{-i}$ $=Q^{*}$ and $\Sigma_{j} b_{j}^{*}=C^{\prime}\left(Q^{*}\right)$, satisfying the Samuelson condition for optimality. 
To form a CSAP for a LCSE, we add an adjustment rule based directly on the first order condition for a linear cost share instrument. Similar to Smith's original rule, lagged quantity demands by others' and others' bids determine personalized prices:

$$
\mathrm{p}_{\mathrm{i}}^{\mathrm{t}+1}=\left(1-\mathrm{s}_{\mathrm{i}}\right) \mathrm{C}^{\prime}\left(\mathrm{Q}_{-\mathrm{i}}{ }^{\mathrm{t}}\right)-\sum_{\mathbf{i} \neq \mathbf{i}} \mathrm{b}_{\mathbf{j}}^{\mathrm{t}} \text {. }
$$

Since these prices do not sum to zero, and each step could be a final outcome, we must normalize prices for a CSE:

$$
p_{i}^{\prime-}=p_{i}^{\cdots}-1 / n<p_{j}{ }^{\cdots}
$$

For equal share parameters $s_{i}$, the Mean Value Theorem implies:

$$
\begin{aligned}
\mathbf{p}_{i}^{\prime t+1} & \approx \frac{n-1}{n^{2}} \sum_{j} C^{\prime \prime}\left(Q_{-i}\right)\left(Q_{-j}^{t}-Q_{-i}^{t}\right)+\left(b_{i}{ }^{t}-1 / n \sum_{j} b_{j}{ }^{t}\right) \\
& =1 / n C^{\prime \prime}\left(Q_{-i}^{t}\right)\left(\bar{Q}^{t}-Q_{i}{ }^{t}\right)+\left(b_{i}^{t}-1 / n \sum_{j} b_{j}{ }^{t}\right)
\end{aligned}
$$

Thus by normalizing, both bid and quantity messages will affect personalized prices. For increasing marginal cost, personalized price will be positive (more than an equal cost share) if: 1) the quantity proposal is less than average; and 2) if the bid is greater than the average bid. That is, the price normalization rule gives an incentive to propose a quantity greater than average and a bid less than average, not the bid incentive that Smith originally intended!

\subsection{Three New CSAPs}

We construct three new CSAPs, two share-taking and one quantity-taking processes, with different message spaces. Two share-taking processes are based directly on the linear cost share instrument: the Quantity Process uses only quantity messages from group participants, and the Bid/Quantity Process uses both bid and quantity messages. The Optimal Bidding Process (OBP) is a quantity-taking process with two types of bid messages, but in contrast to VCM, it is based on the ratio equilibrium (Kaneko, 1977), and so achieves optimality. The ratio equilibrium is a special case of cost share equilibrium with zero personalized prices.

Quantity Process. The name of this process derives from its message space: only quantity messages are transmitted from group members to the coordinator. Given a linear cost share schedule with given personalized price, each member determines her quantity demand $Q_{i}^{t}$. The adjustment rule for personalized price is based on the first order condition for a LCSE; given the current price $p_{i}$, the rule for price adjustment compares one's own demand to the average demand:

$$
\mathrm{p}_{\mathrm{i}}^{\mathrm{t}+1}-\mathrm{p}_{\mathrm{i}}^{\mathrm{t}}=\mathrm{s}_{\mathrm{i}}\left[\mathrm{C}^{\prime}\left(\mathrm{Q}_{\mathrm{i}}{ }^{\mathrm{t}}\right)-\mathrm{C}^{\prime}\left(\overline{\mathrm{Q}}^{\mathrm{t}}\right)\right]
$$

where $\bar{Q}^{t}$ denotes the average of individual demands $Q_{i}^{\mathrm{t}}$ for the current iteration. This adjustment rule will have and equilibrating effect with increasing marginal cost, a common second order condition in economic models. For feasibility, prices must be normalized to sum to zero each step. With equal share parameters $s_{i}$ and applying the mean value theorem, normalized price is: 


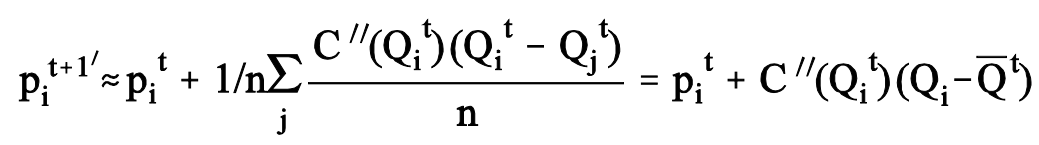

so that with increasing marginal cost, a group member with demands greater than the average demand will receive a higher price on the next round - thus increasing the cost share - and conversely for those with demands lower than the average. This adjustment rule has an equilibrating effect on quantity: with declining marginal willingness to pay, a higher price means a lower quantity demand on the next round.

Bid/Quantity Process. This adjustment process uses both quantity and marginal bid messages from members. Given the personalized cost share schedule, each member first determines their quantity demand $Q_{i}^{t}$. The group quantity is set at the average of member proposals. The marginal bid $b_{i}^{t}$ is the value for member $i$ of marginally increasing this good. Similar to MDP and Bagnoli and McKee, a Provision Point rule is added: if the sum of marginal bids covers marginal cost, the current group quantity is increased.

The price adjustment rule is derived directly from first order conditions for share-taking: price can be determined from the first order condition evaluated at the current group quantity:

$$
p_{i}^{t+1}=b_{i}{ }^{t}-s_{i} C^{\prime}\left(\bar{Q}^{t}\right) \text {. }
$$

For feasibility, prices must be normalized to sum to zero when quantity is not at the equilibrium. The normalized price with equal share parameters is:

$$
\mathrm{p}_{\mathrm{i}}^{\mathrm{t}+1}=\mathrm{p}_{\mathrm{i}}^{\mathrm{t}+1}-1 / \mathrm{n} \sum_{\mathrm{j}} \mathrm{p}_{\mathrm{j}}^{\mathrm{t}+1}=\mathrm{b}_{\mathrm{i}}^{\mathrm{t}}-1 / \mathrm{n} \sum_{\mathrm{j}} \mathrm{b}_{\mathrm{j}}^{\mathrm{t}}
$$

Thus, a person with a bid greater than average will receive a greater price.

Optimal Bidding Process. This process uses only bid messages, but to achieve optimality, two types of bid message are employed. It combines rules suggested in previous studies. Similar to the VCM mechanism, the full bid $B_{i}$ is the voluntary contribution; the sum of full bids determines a feasible shared good level. The marginal bid $b_{i}$ is the willingness to pay to increase the shared good level from the feasible level. The quantity adjustment rule is similar to MDP (Dreze and de Valle Poussin, 1971). The cost allocation rule is similar to Chander (1993).

The method uses a quantity adjustment rule that indicates the direction of the optimum. Personal cost shares are local controllers; they are set to be proportional to bids, a type of fairness rule. For feasibility, the cost share can be less than the full bid, if the sum of full bids is greater than cost. The process is as follows:

1. Given full bids $\mathrm{B}_{\mathrm{i}}^{\mathrm{t}}, \mathrm{QF}$ is the largest quantity that can be afforded for the given sum of full bids. Thus, $\mathrm{QF}^{\mathrm{t}}$ satisfies:

$$
\Sigma B_{i}^{t} \geq C\left(Q^{\dagger}\right)
$$

2. Given $\mathrm{QF}^{\mathrm{t}}$, each member proposes the marginal bid $b_{i}^{t}$ to increase from $\mathrm{QF}^{\mathrm{t}}$ to the next level. 
3a. The suggested quantity $\mathrm{QS}^{\mathrm{t}}$ is determined to be greater than $\mathrm{QF}^{\mathrm{t}}$ if the sum of marginal bids exceeds marginal cost:

$$
\dot{\mathrm{QS}}=\gamma\left[\sum \mathrm{b}_{\mathrm{i}}^{\mathrm{t}}-\mathrm{C}^{\prime}\left(\mathrm{QF}^{\mathrm{t}}\right)\right]
$$

3b. The suggested cost share parameters are as follows:

$$
\begin{gathered}
\mathrm{s}_{\mathrm{i}}{ }^{\mathrm{t}}=\frac{\mathrm{B}_{\mathrm{i}}^{\mathrm{t}}+\mathrm{b}_{\mathrm{i}}^{\mathrm{t}}}{\sum\left(\mathrm{B}_{\mathrm{i}}{ }^{\mathrm{t}}+\mathrm{b}_{\mathrm{i}}{ }^{\mathrm{t}}\right)} \text { if } \mathrm{QS}>\mathrm{QF} ; \\
\mathrm{s}_{\mathrm{i}}{ }^{\mathrm{t}}=\frac{\mathrm{B}_{\mathrm{i}}{ }^{\mathrm{t}}}{\sum \mathrm{B}_{\mathrm{i}}^{\mathrm{t}}} \quad \text { if } \mathrm{QS} \leq \mathrm{QF} .
\end{gathered}
$$

The suggested cost share $S T_{i}^{t+1}$ is the suggested share times the cost of the suggested quantity:

$$
\mathrm{ST}_{\mathrm{i}}^{\mathrm{t}+1}=\mathrm{s}_{\mathrm{i}}{ }^{\mathrm{t}} \mathrm{C}\left(\mathrm{QS}^{\mathrm{t}}\right)
$$

The process repeats, and the suggested cost share can become the "full bid" contribution for the next round. The process stops when $Q S$ and full bids are no longer changing. At an equilibrium, the resulting cost shares are proportional to bids.

When quantity increases, this process is utility-improving similar to the MDP process, since bidding is voluntary and the cost share will be no greater than the full bid. ${ }^{16}$ However, utility improvement is not guaranteed if quantity decreases.

\subsection{Simulation of Alternative CSAPs}

We use simulation to compare alternative CSAPs for convergence, optimality, and individual rationality. While simulation outcomes do not constitute proof, either non-convergence or non-optimality is sufficient to negate the possibility of global optimality of a process.

All simulations shown in Table 2 use the same Cobb-Douglas utility functions and a cubic cost function with a fixed cost. Utility functions are specified so that one group member is LH for benefit and endowment respectively, one is HL, and one is LL. Simulation uses "truthful" messages regarding bids. For all share-taking CSAPs, the starting point is equal shares $\left(s_{i}=1 / n\right.$ and $p_{i}=0$ ). Convergence means that quantity proposals and/or bids are no longer changing, here no change in the first two decimal places. Convergence details are shown in Appendix 1.

Selection of adjustment or penalty parameters is a disadvantage for implementing GL, MDP, and OBP processes. For the MDP process, quantity does not arise from individual choice, so the adjustment rule may give a quantity not afforded by some group members. For our example, the MDP process was infeasible for a wide range of adjustment speeds (including $\gamma=1$, as MDP is

\footnotetext{
${ }^{16}$ Utility improvement occurs when QS increases:$$
\mathrm{u}^{\mathrm{i}}\left(\mathrm{M}_{\mathrm{i}}-\mathrm{ST}_{\mathrm{i}}, \mathrm{QS}\right) \geq \mathrm{u}\left(\mathrm{M}_{\mathrm{i}}-\left(\mathrm{T}_{\mathrm{i}}+\mathrm{b}_{\mathrm{i}}\right), \mathrm{QS}\right)=\mathrm{u}^{\mathrm{i}}\left(\mathrm{M}_{\mathrm{i}}-\mathrm{T}_{\mathrm{i}}, \mathrm{QF}\right) \geq \mathrm{u}^{\mathrm{i}}\left(\mathrm{M}_{\mathrm{i}}-\mathrm{B}_{\mathrm{i}}, \mathrm{QF}\right) \text {. }
$$ 
usually described). For $\gamma=.05$, there was an equilibrium - when bids and quantity were no longer changing - but the equilibrium quantity was $77 \%$ of the optimum quantity.

For this nonlinear cost and the penalty parameter $\gamma=5,{ }^{17}$ the GL process converged to a non-optimal disagreement point in which the low-income, low-benefit member sticks to a low demand in spite of the penalty. Since this group member would be made worse off compared to her non-cooperative solution at this equilibrium, she would not voluntarily agree to the GL equilibrium outcome. Non-optimality occurred for both higher and lower penalty parameters.

The Smith process and our three new processes converged successfully. The BQP and Smith process have the same message space - bids and quantities - and converged similarly. Evidently for share-taking, faster convergence can be obtained with a larger message space: the QP took much longer to converge, close to optimal by iteration 11, whereas BQP converged in only five iterations. OBP took 18 iterations to converge with the same size message space.

\subsection{Behavioral Effects of CSAPs}

Since the Quantity Process, Smith Process, Bid-Quantity Process, and Optimal Bidding Process converged successfully, they were further compared behaviorally. Experimental results show that behavior and computation differ: what works computationally may work less well when behavior is introduced. Our experimental design includes both the application of CSAP rules and the specification of information and voting rules. Although Smith's work $(1978,1979,1980)$ is a major influence, our experimental design differs importantly in terms of voting rules.

\subsection{Proposal and Approval Phases with Unanimity Voting}

Unanimity as a voting mechanism has been featured in both conceptual and experimental economic literature. Economic experiments for public goods have indicated that unanimity voting can improve outcomes. Unanimity voting in another setting has been found to greatly enhance the efficiency of group outcomes (Gardner, Herr, Otrom, and Walker, 2000). Unanimity voting is an important feature of our experimental design which may ameliorate free-riding behavior because logically, any extreme proposals would not be selected by a group.

Our unanimity voting method differs from Smith's. In Smith's experiments, there were repeated rounds, and the round receiving unanimous votes for termination of the process was taken as the group outcome. Here - as in a natural group process - there are two types of voting: to end proposal generation and then to select among the generated proposals. That any proposal may be an outcome is allowed because each proposal round is feasible, by construction. Unanimity is required both to end proposal generation and to select the group outcome from the set of proposals.

Correspondingly, the experimental cost sharing game has two defined phases: a Proposal Phase and an Approval Phase. Cost allocation and adjustment rules operate during the Proposal Phase to generate alternative group plans. The Approval Phase then allows groups to review and vote over the entire set of group proposals. Because there are these two phases, any strategic

\footnotetext{
${ }^{17}$ Chen and Plott (1996) used $\gamma=1$ and 100, suggesting that a higher parameter leads to faster convergence.
} 
behavior in generating proposals can be separated from group decision. That is, although a group member may strategize in generating proposals, this need not destroy the final outcome. Still, strategic behavior during the Proposal Phase may have a destructive influence on group decision during the Approval Phase, as shown in examples of group processes given here.

The Approval Phase is constructed similar to Hare voting: each member first indicates the three most preferred proposals by rank. A screen with ranking information for all group members is then presented. Plans that are not in someone's top three are dropped from consideration. Members are then given three chances at approval voting - "yes" or "no" votes - for the remaining set, each time with a display of how group members voted. If there is no group agreement, all group members receive their non-cooperative allocations, which is by construction less desirable.

\subsection{Parameterization and Experimental Set-up}

Following Smith (1976), group members' rewards are based on pre-specified cost and utility functions and given endowments. University of Arizona business school students were used as subjects. Experimental cost for each session was about $\$ 300$ based on an average of about $\$ 15$ per subject plus a $\$ 5$ show up fee. Each group had three members. Following Andreoni (1988), to avoid learning about group members, group membership was mixed randomly after the first game. Each group participated in a practice game with no payoff, followed by three games with real rewards. All groups in a session of three games played simultaneously, but the network set-up assured anonymity. Each session of practice and three games took about two hours in total.

Cost and Parameters. The cost function is nonlinear with a fixed cost $f$ of the form: $\mathrm{C}(\mathrm{Q})=$ $1 / \mathrm{s}\left[\mathrm{f}+10(\mathrm{sQ})-5\left(\mathrm{sQ}^{2)}+5(\mathrm{sQ})^{3}\right]\right.$. Reward levels are determined by quasi-linear utility functions of the form: $\mathrm{u}_{\mathrm{i}}\left(\mathrm{x}_{\mathrm{i}}, \mathrm{Q}\right)=\mathrm{x}_{\mathrm{i}}+\gamma_{\mathrm{i}} / \mathrm{s} \log (1+\mathrm{sQ})$. Fixed cost $f$ and scaling factor $s$ were varied to provide games with different optimal $Q$ levels and different status quo for members.

For information presentation purposes, experiments use discrete levels of possible quantities, so that rather than continuous schedules for cost and rewards, discrete levels correspond to quantity levels for incremental cost shares are net rewards.

Heterogeneous Member types. There were three types of members in each game: $\mathrm{A}=$ (High Reward, Low Endowment; indicated as HL); B= (High Reward, High Endowment; indicated as $\mathrm{HH}$ ); $\mathrm{C}=($ Low Reward, Low Endowment; indicated as LL). In each game, two of the members could not afford to provide the good individually. For each participant, her type was varied over the course of the three games.

Information. Compared to VCM treatments, ours is a "worst case" communication setting: there is no direct communication among group members, bid messages are simultaneous, and cost shares are private. At any point group members could view the history of proposal generation in a format similar to information in Table 3 through Table 6, except that payoff (net reward) information was private.

For share-taking, each group member receives a schedule of quantities with corresponding personalized cost shares and rewards. Similar to VCM, the information format for the Optimal 
Bidding Process uses a matrix of outcomes for "your bid" and "others' bids" indicating the possible levels of the shared good and payoffs corresponding to combinations of bid amounts.

At the beginning of each game session, each member identifies her non-cooperative best outcome for the given cost and utility schedules. For the non-cooperative outcome, the full cost for her optimal quantity must be paid by the individual. On all information screens, the individual's non-cooperative net reward level reminds her of the benefits of cooperation.

Rules. Experiment descriptions of allocation and adjustment rules for each process are given in Appendix 1. To summarize, the price adjustment rule for the Quantity Process gives an incentive to propose quantities less than average, while adjustment for Bid-Quantity pricing gives an incentive for the incremental bid to be less than average. For the Smith-like process (not actually like Smith's intended incentive scheme), because of the need for feasibility for each proposal round, price normalization gives a two-pronged incentive based on both bids and quantities, giving opportunity for two forms of strategic behavior.

The Provision Point rule for the Bid/Quantity and Smith-like processes is that the group quantity is allowed to increase to the next level only if the sum of incremental bids exceeds the incremental cost for the given level. A consideration for experimental design is how to specify the base for the Provision Point test. For the Smith-like process, we used the group average roundeddown; this led to negative bids in part because disadvantaged group members would want less than the average. For the Bid/Quantity process, we used the group average less one level for the provision test; this seemed to give more satisfactory bidding results.

For share-taking processes, the Proposal Phase starts from equal cost shares for each group member. Each round produces a proposal for group quantity and cost shares for the next round. If the group does not agree to stop the proposal rounds within a certain number of rounds, then the proposal process has a randomized end, similar to breakdown for a natural process. Subjects were told that the Proposal Phase would end with probability of 0.5 after five proposal rounds.

During the Approval Phase, multiple "yes" votes were permissible, so that approvals for multiple group choices were possible. With multiple approvals, experiment payoffs were made according to the approved proposal with the smallest quantity variance over group members. For Optimal Bidding, the payoff was based on the largest feasible quantity.

Optimal Bidding Process. For the Optimal Bidding Process (OBP), each round produces a proposal of a feasible group quantity and cost shares as well as a suggested direction for an improved outcome together with suggested cost shares. However, group members are free to make any bid each round.

The adjustment rule for OBP differs from that in Section 6 because experiments used discrete rather than continuous quantity levels. Quantity adjustment is similar to the method proposed by Tulkens (1978) and the Provision Point rule of Bagnoli et al. (1991, 1992). For suggested good level QS and feasible level QF and incremental cost denoted by IC:

$$
\begin{aligned}
& \mathrm{QS}=\mathrm{QF}+1 \text { if } \Sigma \mathrm{b}_{\mathbf{i}}{ }^{\mathrm{t}}-\mathrm{IC}\left(\mathrm{QF}^{\mathfrak{t}}\right)>0 ; \\
& \mathrm{QS}=\mathrm{QF} \quad \text { if } \Sigma \mathrm{b}_{\mathrm{i}}{ }^{\mathrm{t}}-\mathrm{IC}\left(\mathrm{QF}^{\mathrm{t}}\right)=0 ; \\
& \mathrm{QS}=\mathrm{QF}-1 \text { if } \Sigma \mathrm{b}_{\mathbf{i}}{ }^{\mathrm{t}}-\mathrm{IC}\left(\mathrm{QF}^{\mathrm{t}}\right)<0 .
\end{aligned}
$$




\subsection{Strategic Behavior and Fairness: Examples of Experimental Institutions}

To demonstrate alternative rule sets or institutions and resulting behavior, Tables 3-6 show examples of actual game histories for each of our experimental cost sharing institutions, demonstrating the types of strategic behavior that can occur. ${ }^{18}$ These examples indicate that many types of individual behavior occur for each institution. As forms of strategic behavior, both underbidding and overbidding are exhibited, and the same player may exhibit both in different rounds. However, in spite of individual strategic behavior, a reasonable group outcome can occur for the Approval Phase.

Table 3 shows an example of history for the Quantity Process. Besides approval of the cost share equilibrium, other outcomes were also approved, as indicated by unanimous "yes" votes. This exemplary outcome of the group finding the cost share equilibrium was obtained in slightly less than half of the experimental games with the Quantity process.

The approved outcomes were individually rational: all three group members are better off compared to their best individual outcomes. The group outcome seems fair: the B member $(\mathrm{HH})$ receives the largest cost share, the $\mathrm{A}$ member (HL) has an intermediate share, and the $\mathrm{C}$ member (LL) has the lowest share. The disadvantaged "C" member (LL) starts out with a lower than average quantity proposal and continues this for four rounds; consequently this member receives a much lower cost share than the other group members.

Table 4 shows history for Game 2 for a Bid/Quantity game session. The provision test is carried out for the group average level minus one. To illustrate the provision rule: in Round 1 the rounded average of member proposals is $\bar{Q}=4$; one level less is $Q=3$, which can be increased to $Q=4$ if the sum of incremental bids exceeds incremental cost. Since the provision test is passed, $Q=4$ is the group quantity for round 1 . For the next round, the average is $Q=6$, but the provision test is not passed so the group quantity is set at $Q=5$ where it remains until the last round when group members unanimously agree to a group quantity of $Q=6$ for the indicated cost shares. This last round quantity is less than the actual optimum $Q=7$ because of strategic behavior.

Evidently, the larger message space with both bids and quantities gives more opportunity for strategic behavior. In Round 1, the disadvantaged C member (LL) starts out by proposing a quantity much less than the other members' proposals. Over the rounds, this person also presents negative incremental bids, evidently desiring a quantity less than the group average. Consequently, this member receives the lowest cost share on all rounds. Group member A (HL) initially proposes larger quantities than the others but later reduces quantity proposals; this member also puts in larger incremental bids for most rounds; consequently this member receives the largest cost shares except in Round 6, after this member reduced her bid on the previous round. The advantaged B member $(\mathrm{HH})$ plays strategically as indicated by relatively low bid messages, so that the B member does not have the largest cost share, except in round 6 from A's reduced bid on the previous round.

\footnotetext{
${ }^{18}$ The number of trials for comparison was limited for budgetary reasons but are comparable to past experiment research.
} 
Table 5 shows history for Game 3 from an Optimal Bidding game session. There are more rounds than in the QP and BQP cases, indicating more strategic behavior. Repeatedly because the Provision Point test is satisfied, the algorithm signals that the optimum is greater than $Q=3$. In Round 2 the optimum $Q=4$ is found, however the group votes to continue the messaging process. Similar to VCM results, note the decay in the suggested plan from Round 2 through Round 5, after which A and B members dramatically increase their full bids. All members have erratic patterns for "full" bids, evidently strategic behavior. However, all Provision Point tests are passed except (correctly) for Round 6 when the feasible plan exceeds the optimum. Evidently, group members are able to distinguish the roles of the two types of bidding.

Voting over all rounds, the optimal level $(Q=4)$ with unequal cost shares is accepted, i.e., in spite of strategic behavior, the optimum is achieved. Regarding fairness, the advantaged B member receives the largest share of cost in the approved outcomes. The similar A and C members have cost shares of similar magnitude in the approved last two rounds.

Table 6 shows history for Game 1 for the Smith-like Process in which the Provision Point test was carried out at the group average. For example in Round 1, the average of proposals (rounded down) is $Q=7$; the provision test is whether or not the group plan should be increased to $Q=8$. The negative provision result means that the group plan remains at $Q=7$.

The pricing incentive rule is based on both bids and quantities, giving an increased cost share to members who propose a lower quantity than average and have incremental bids more than the average. This two-pronged incentive gives more opportunity for strategizing. For example, the disadvantaged $\mathrm{C}$ member gives the lowest quantity proposals and so is penalized with relatively large cost shares. Member A gives a large incremental bid on Round 1, thus receiving a cost share of over $90 \%$ on the following round, and then reduces her bid to zero on the next round to reduce her cost share. The advantaged member B consistently proposes $Q=9$ which is greater than the group average and also presents negative incremental bids; she therefore consistently has low or subsidized cost shares. The resulting cost share distributions are wildly unequal and seem unfair.

In Approval Voting, the disadvantaged $\mathrm{C}$ member prefers the equal shares outcome for the first round because her payoff is highest; all other proposals are voted down by this member, even though they are associated with higher payoffs than the non-cooperative outcome, probably because of the skewed cost shares. Member A member has the same voting pattern. Since Member B does not agree to equal shares, probably because the other rounds have higher payoffs, there is no group agreement. Disagreement can be attributed to the great inequity in cost shares due to strategic behavior. In spite of its lack of agreement, this trial illustrates that group members appear to understand the complicated incentives of this game structure.

Tables 3-6 about here

\subsection{Comparison of Experimental Institutions}

We compare alternative institutions in terms of the group decision criteria of efficiency, transactions costs, and rate of agreement. Efficiency is measured in terms of the percent of the optimal solution for shared good, with "zero" used in cases of no group agreement. The rate of 
agreement is another indicator of success: more "no agreement" games indicates less success. The number of proposal rounds is a measure of transactions costs. Here, the average number of proposal rounds ranged from four to six rounds, probably influenced by the rule of a randomized end after five rounds. In theory for the cost and utility specifications, a solution could have been obtained in three rounds.

For each institution, there was one experiment session with three games for three to five groups at the same time. ${ }^{19}$ Table 7 shows the number of groups for each institution and summarizes the results. Each of the three games for each institution has a different parameterization of utility and cost, with respective optimal solutions of $Q=8,7$, and 4 .

Table 7 about here

Quantity Process. The Quantity Process had the most success in finding a group solution: the Quantity Process achieved 94\% efficiency and 100\% agreement for nine games in initial experiments. The smaller message space of the QP may be associated with fewer opportunities for strategic behavior, and its simpler adjustment rule requires less learning.

Bid/Quantity Process (Provision Point test at $\bar{Q}-1$ ). This process is similar to the Smith Free-Rider mechanism, except for the addition of the Provision Point test and different voting rules. With strategic behavior, because the Provision Point test was met only about half the time, group outcomes were generally less than the optimal outcomes. Although bids were usually insufficient to meet the provision test, bids were positive most of the time.

Smith-like Process (Provision Point test at group average $\overline{\mathrm{Q}}$ ). This process had the highest rate of negative or zero bids, and there was no agreement in about a third of the games. Because of more "no agreement" outcomes, efficiency of this rule was the lowest of these four institutions. The nature of the Provision Point test was evidently a factor

Optimal Bidding Process (Provision Point test at QF). This process is like VCM with the addition of marginal bids and the provision point. This process had the highest efficiency (69\%) among the three compared CSAPs with bidding. Its rate of satisfying the provision test is also best among these three methods. The percent of negative or zero bids was about the same as for the Bid/Quantity Process, but OBP was better than the Bid/Quantity process and the Smith-like process in terms of the rate of finding agreement.

In comparison, some voluntary contribution experiments with simultaneous bidding (Coates and Gronberg, 1996, 2001) had efficiencies as low as 44-50\%. The 69\% average efficiency for the OBP games - with simultaneous messaging - compares favorably to VCM studies with simultaneous messaging (60\% efficiency for Chan, 1999, 1996). While providing only aggregate information about others' contributions, OBP efficiency was comparable to VCM with more specific information about individual contributions (70\% by Sell and Wilson, 1991).

\footnotetext{
${ }^{19}$ Although trials for each institution were limited to a small number, the total number of games was similar to Smith's 1979 study.
} 
Thus, even our limited number of experiments indicates that the nature of the message space and institutional rules matter. The Bid/Quantity and Smith-like games have the same message spaces but different rules; approval rates are strikingly different for these two processes. All methods with bidding exhibited more indicators of strategic behavior than the Quantity Process: processes with bidding had disagreement rates of 13-33\% whereas the initial Quantity Process games all had group agreement.

\subsection{More Experiments for the Quantity Process}

Because of its relative success, the Quantity Process was further examined in 144 more games. For this larger set of experiments, an average efficiency of $77 \%$ and success rate of group agreement of $85.5 \%$ were obtained, but certain computational problems were revealed. Experimental results summarized in Table 8 are described below.

Efficiency and Learning Effects. Efficiency results - an average of $77 \%$ over all games are on the same order as Smith's (1979) Auction and Free-rider mechanisms, here for a more complex environment with nonlinear cost. Efficiency varied by game, with the second game statistically less efficient than the first and third games. The lower efficiency of the second game may be due to more strategic behavior as members "play" with the message possibilities. By the third game when rules are probably better understood, an average efficiency of $83 \%$ is attained.

Learning effects are evident from the statistical tests indicated in Table 8. There are significant differences - at the $99 \%$ probability level using a t-test between game 1 and game 2 in the number of proposal rounds and the approval rates for equal shares. There is a significant increase in efficiency between game 1 and game 2, at the 95\% probability level for the t-test.

Bid vs. Quantity Messaging. We hypothesized that the form of messaging can affect the success of group process and suggested that there may be more strategic behavior for institutions with bidding. By combining all QP games and also combining all games with bidding in some form, we test this hypothesis - with a binomial distribution model - of whether there is more disagreement for processes with bidding than for QP with "quantity only" messaging. Using a ttest for the difference in disagreement rates at a probability level of $99 \%$, disagreement rates for bidding differ significantly from rates with quantity messaging, and games with bidding have a significantly higher disagreement rate. ${ }^{20}$

Potential Subsidized Cost Shares. Examining this more extensive set of experimental trials, a problem with the adjustment rule is evident: the adjustment rule can result in a subsidized cost share for a game participant with a low quantity demand, which in turn can lead to group disagreement. Nearly half of the indicated "disagreement" cases were associated with outcomes in

\footnotetext{
${ }^{20}$ There were 153 total games with "quantity only" messaging and 39 games with bid messaging of some form. The average disagreement rate over all bidding games was $20.38 \%$. The average disagreement rate over all QP games was $13.6 \%$. The t-statistic is $0.0678 / 0.00695$ for a t-statistic of 9.75 ! (The standard deviation for the disagreement rate over combined experiments is .00695.)
} 
which one group member was subsidized. ${ }^{21}$ However, subsidies did not always preclude agreement if the advantage of group agreement was sufficient for the other group members. (Other disagreement cases were due to voting problems: either a non-compromising member held out for her most preferred outcome, or there seemed to be a lack of understanding of the voting process.)

Heterogeneity Information. Providing detailed heterogeneity information could help promote the idea that cost shares can be fair even though unequal, because endowments and preferences differ. Initially games were differentiated to test for the effect of information about heterogeneity. In one set of games, only a generic description was given that group member types differed. In the other set, more detailed heterogeneity information was given: each group member was told specifically about their own type (high or low endowment, and high or low reward) relative to the types of others. Since none of the indicators shown in Table 8 had a statistical difference by information treatment, outcomes for the two information treatments were combined.

Group Agreement and Bidding Effects. The importance of group agreement should be emphasized as a criterion for success in addition to efficiency measures used in experiments. (Recall that many public goods experiments that tested for the free-rider problem were not structured for group agreement.) Here and in natural settings, without agreement no shared good is provided. Group agreement was found in $85.5 \%$ of the 144 QP games. Failure to reach a group agreement occurred in 12/69 (17.3\%) games with "no heterogeneity information" and in 9/75 $(12 \%)$ of the "heterogeneity information" games; this difference was not statistically significant.

Transactions Costs as Measured by Proposal Rounds. Each game equilibrium could be found in three proposal rounds if proposals were truthful; any strategic behavior would increase the number of rounds. The number of rounds for the second and third games (4 to 5 rounds) is significantly greater than for the first game, indicating more "strategic play" in later games as rules are better understood.

Equal Shares Approval. Equal cost sharing was the starting point for each game. The overall approval rate for equal shares is $31 \%$, indicating that equal sharing of cost is a robust sharing rule even with heterogeneity. The highest approval rate for equal shares is for the first game, and the lowest rate is for the second game. Reasonably, equal cost sharing may be more attractive when an alternative sharing rule is not transparent.

Cost Share Equilibrium. The concept of a cost share equilibrium was not specifically described in instructions. We had expected that a solution with unanimity in quantity (QU) for determined cost shares would be a natural attractant, with only an issue of locating it. However, a located QU outcome was not necessarily approved for the determined cost shares. An outcome with unanimity in quantity for the determined shares was not necessarily the theoretical CSE because of strategic behavior coupled with the adjustment rules.

21 The subsidy situation could be addressed by changing the starting point of the QP process, eg. instead of starting with equal shares letting initial shares depend on endowments. But this would require the use of private information about group members' endowments. 
A QU for given cost shares was located in $46 \%$ of the games. The second and third games had a statistically greater rate of locating a QU compared to the first game, evidently a learning effect. The average approval rate for quantity unanimity (QU) is $21 \%$, with the lowest rate $(10 \%)$ on the first game; the second game has the QU highest approval rate $(31 \%)$. At the same time, the highest approval rate for equal shares is on the first game.

Given that QU is not found in every game, the conditional rate of approval - QU approval given that unanimity is located - is a more reasonable measure of QU attractiveness. The QU conditional approval rate averages $46 \%$ compared to $31 \%$ average approval for equal shares.

Perhaps QU approval could be improved by algorithmic changes: in $83.3 \%$ of the cases in which a located QU was not approved, there were either subsidies or an imbalance in cost share allocation relative to player types.

\subsection{Conclusions}

The situation of nonlinear cost - such as economies of scale and fixed costs - is a reason for a group to benefit from cost sharing for a jointly provided good, but it makes finding a group solution difficult through democratic process especially when there is heterogeneity in group preferences and endowments. Therefore, this paper proposed the concept of a cost share adjustment process (CSAP), an algorithmic process to adjust parameters of a cost share system to help a group locate a feasible agreement about a shared good. We developed a both a conceptual foundation and a design approach for CSAPs. The design approach addresses impossibility results of mechanism design: since there is no perfect theoretical solution, both computation and behavior influence the desirability of a potential process. The design approach compares alternative cost sharing institutions via simulation and experiment, applying group decision criteria of optimality, feasibility, convergence, fairness, transactions costs, and agreement rate.

We identified two generic types of processes (share-taking and quantity-taking). We showed that share-taking built on a cost share system and personalized prices is inherently optimal and feasible, whereas quantity-taking with bidding may not be. We identified important taxonomic design elements for CSAPs: message space, cost allocation rules, controllers, and personalized price adjustment rules. CSAPs can exhibit many possible combinations of these aspects. In contrast to the Voluntary Contribution Mechanism commonly used in public good experiments, our Optimal Bidding Process based on two types of bid messages is optimal in theory and works well in practice for a nonlinear environment.

Our experiments identified a behavioral aspect of message space design. Although CSAPs with either quantity or bid messaging can produce theoretical optimality, comparing CSAPs experimentally in terms of message space showed that bidding significantly resulted in more breakdown of group agreement compared to quantity messaging. But the quantity process could also result in no agreement if the underlying (imperfect) adjustment algorithm produced unfairseeming subsidies.

Experiments with our three new CSAPs had reasonable success for nonlinear cost, compared to past public good experiments with linear cost functions. In spite of a relatively 
unfavorable information setting - no face-to-face communication and simultaneous messaging our experimental trials had average efficiencies of $65 \%$ and $69 \%$ with bidding over twelve to fifteen games, and average efficiency of $77 \%$ for the Quantity process over 144 games.

Our experimental design mimics a natural group decision structure of having separate Proposal and Approval phases. A CSAP operates during the Proposal Phase to generate alternative proposals for shared good level and cost shares, and the approval voting process then allows group members to choose among alternative proposals. Results indicate that proposal generation together with unanimity approval voting - can temper strategic behavior without complex penalty functions, producing near-optimal outcomes. Thus, approval voting is more than an experimental artifact: it is an important institutional design aspect to ameliorate strategic behavior. Since there are many ways that approval voting could be structured, further consideration of voting rules - a prominent feature of political science literature - is warranted.

A natural follow-up question is, how could the CSAP/ voting approach be applied as decision support for real group decision situations? A CSAP could be used either with full anonymity in computer-mediated communication or in a face-to-face mode. The Quantity Process is simple enough for computations to be made by hand, an advantage for non-automated groups especially with small group size. For larger group sizes, a computer-mediated group decision support system based on a CSAP could substantially improve group outcomes. With GDSS implementation as an eventual goal, CSAP design should be further studied in both experimental and natural settings. 
Table 1. Taxonomic Comparison of Alternative Cost Share Adjustment Processes

\begin{tabular}{|c|c|c|c|c|}
\hline Process & $\begin{array}{l}\text { Control } \\
\text { Instrument }\end{array}$ & $\begin{array}{l}\text { Cost } \\
\text { Information } \\
\text { given to Group } \\
\text { Members }\end{array}$ & $\begin{array}{l}\text { Group } \\
\text { Member's } \\
\text { Message }\end{array}$ & Incentive Rule \\
\hline \multicolumn{5}{|l|}{ Share-taking: } \\
\hline Groves-Ledyard $^{a, b}$ & Personalized price & $\begin{array}{l}\text { Personal cost } \\
\text { share schedule }\end{array}$ & Quantity demand & $\begin{array}{l}\text { Form of cost } \\
\text { share rule }\end{array}$ \\
\hline Quantity $^{*}$ & Personalized price & $\begin{array}{l}\text { Personal cost } \\
\text { share schedule }\end{array}$ & Quantity demand & None \\
\hline Smith $^{a, b}$ & $\begin{array}{l}\text { Personalized price; } \\
\text { Group quantity }\end{array}$ & $\begin{array}{l}\text { Personal cost } \\
\text { share schedule }\end{array}$ & $\begin{array}{l}\text { Quantity demand; } \\
\text { Marginal bid }\end{array}$ & $\begin{array}{l}\text { Form of cost } \\
\text { share rule }\end{array}$ \\
\hline $\begin{array}{l}\text { Bid/ } \\
\text { Quantity }^{*}\end{array}$ & $\begin{array}{l}\text { Personalized price; } \\
\text { Group quantity }\end{array}$ & $\begin{array}{l}\text { Personal cost } \\
\text { share schedule }\end{array}$ & $\begin{array}{l}\text { Quantity demand; } \\
\text { Marginal bid }\end{array}$ & $\begin{array}{l}\text { Provision Point } \\
\text { rule }\end{array}$ \\
\hline \multicolumn{5}{|l|}{ Quantity-taking: } \\
\hline$M D P^{a,}$ & Group quantity & $\begin{array}{l}\text { Individual's } \\
\text { tax bill }\end{array}$ & Marginal bid & None \\
\hline Optimal Bidding & $\begin{array}{l}\text { Group quantity; } \\
\text { Personalized shares }\end{array}$ & $\begin{array}{l}\text { Matrix of } \\
\text { feasible } \\
\text { quantities, for } \\
\text { combinations } \\
\text { of individual's } \\
\text { bids and sum of } \\
\text { others' bids }\end{array}$ & $\begin{array}{l}\text { Full bid; } \\
\text { Marginal bid }\end{array}$ & $\begin{array}{l}\text { Provision Point } \\
\text { rule }\end{array}$ \\
\hline
\end{tabular}

${ }^{a}$ Original process modified for nonlinear cost

${ }^{\mathrm{b}}$ Converted to a CSAP by adding a personalized price adjustment rule

* New process in this paper 
Table 2. Simulation of Cost Share Adjustment Process for Nonlinear Cost.

\begin{tabular}{|c|c|c|c|}
\hline Process & Iterations to Converge & $\begin{array}{l}\text { Individual } \\
\text { Rationality }\end{array}$ & Pareto Optimal \\
\hline Groves-Ledyard ${ }^{a c}$ & $\begin{array}{c}7 \\
\text { (stable disagreement) }\end{array}$ & No & $\begin{array}{c}\text { No } \\
\text { (96\% of optimal } \\
\text { quantity) }\end{array}$ \\
\hline Quantity $^{c}$ & 23 & Yes & Yes \\
\hline Smith $^{c}$ & 7 & Yes & Yes \\
\hline Bid/Quantity ${ }^{c}$ & 5 & Yes & Yes \\
\hline$M D P^{b}$ & 6 & Yes & $\begin{array}{c}\text { No } \\
\text { (77\% of optimal } \\
\text { quantity) }\end{array}$ \\
\hline Optimal Bidding $^{b}$ & 18 & Yes & Yes \\
\hline
\end{tabular}

${ }^{\text {a }}$ Penalty parameter: $\gamma=5$

${ }^{\mathrm{b}}$ Speed of adjustment: $\gamma=.05$

${ }^{c}$ Equal share parameters

Utility functions: $u_{i}\left(x_{i}, Q\right)=\log \left(1+x_{i}\right)+\gamma_{i} \log (1+Q)$.

Preference parameters: $\gamma_{1}=1, \gamma_{2}=2, \gamma_{3}=1$.

Endowments: $M_{1}=20, M_{2}=10, M_{3}=10$.

Cost function: $C(Q)=10+10 Q-5 Q^{2}+5 Q^{3}$ for $Q>0$;

$$
C(0) \equiv 0 \text {. }
$$


Table 3. Example of Quantity Process, Game 1, Optimal $Q=8$

\begin{tabular}{|r|r|r|r|r||r|r|r|r|r|r|r|r|r|}
\hline Round & $\begin{array}{r}\text { Group } \\
\text { Plan }\end{array}$ & \multicolumn{3}{|c|}{ Member Proposals } & \multicolumn{3}{|c|}{ \% Cost Shares } & \multicolumn{3}{|c|}{ Member Payoffs } & \multicolumn{3}{|l|}{ Final Approval Votes } \\
\hline & & A & B & C & A & B & C & A & B & C & A & B & C \\
\hline 1 & 7 & 8 & 9 & 6 & 33 & 33 & 33 & 5857 & 9437 & 2697 & Yes & Yes & No \\
\hline 2 & 7 & 8 & 8 & 7 & 36 & 46 & 18 & 5790 & 9090 & 3110 & Yes & Yes & No \\
\hline 3 & 7 & 8 & 8 & 7 & 39 & 50 & 11 & 5699 & 8999 & 3288 & Yes & Yes & Yes \\
\hline 4 & 7 & 8 & 8 & 7 & 43 & 53 & 4 & 5612 & 8912 & 3470 & Yes & Yes & Yes \\
\hline 5 & 8 & 8 & 8 & 8 & 45 & 54 & 1 & 5579 & 8949 & 3661 & Yes & Yes & Yes \\
\hline & & & & & & & $\begin{array}{r}\text { non- } \\
\text { coop }\end{array}$ & 4220 & 7710 & 2000 & & & \\
\hline
\end{tabular}


Table 4. Example of Bid/Quantity Process, Game 2, Optimal $Q=7$, Provision Point Test at Group Average -1

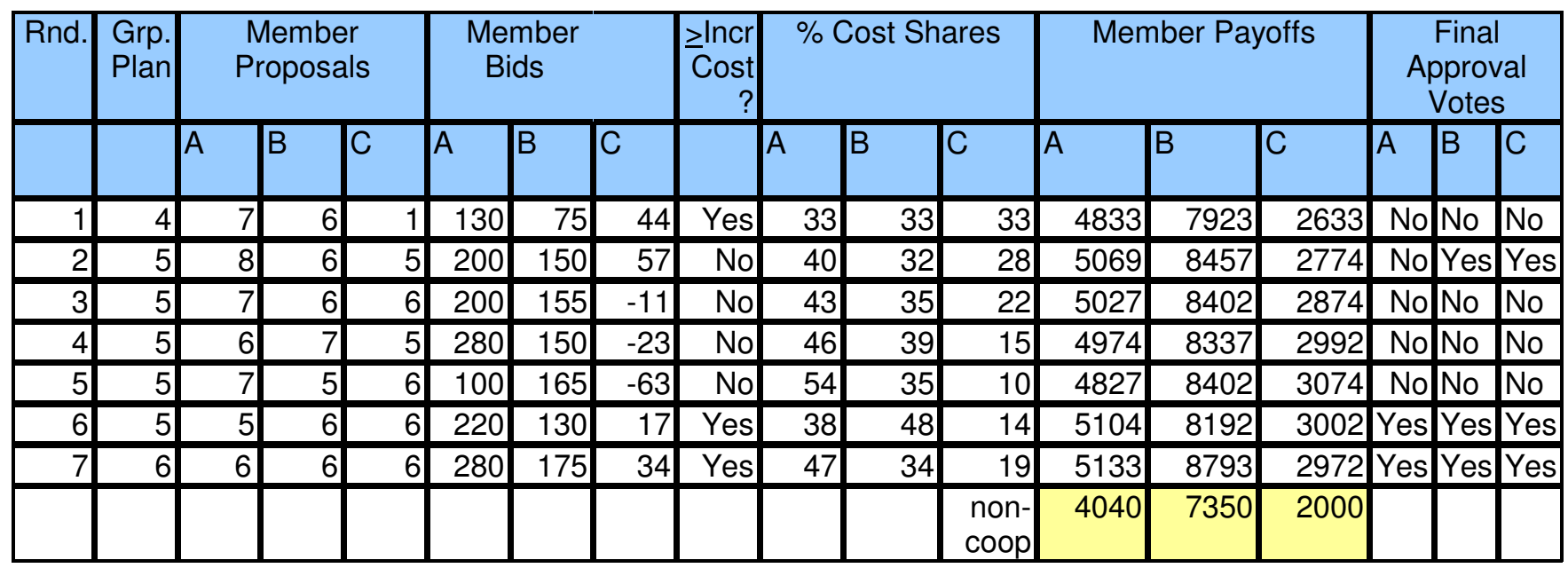


Table 5. Example of Optimal Bidding Process, Game 3, Optimal Q=4, Provision Point Test at Feasible Plan

\begin{tabular}{|c|c|c|c|c|c|c|c|c|c|c|c|c|c|c|c|c|c|c|}
\hline \multirow[t]{2}{*}{ Rnd. } & \multirow[t]{2}{*}{$\begin{array}{l}\text { Feas } \\
\text { Plan }\end{array}$} & \multirow[t]{2}{*}{$\begin{array}{l}\text { Sgstd } \\
\text { Plan }\end{array}$} & \multicolumn{3}{|c|}{ Full Bids } & \multicolumn{3}{|c|}{$\begin{array}{l}\text { Incremental } \\
\text { Bids }\end{array}$} & \multirow{2}{*}{$\begin{array}{l}\geq \\
\text { Incr. } \\
\text { Cost? }\end{array}$} & \multicolumn{3}{|c|}{ \% Cost Shares } & \multicolumn{3}{|c|}{ Member Payoffs } & \multicolumn{3}{|c|}{$\begin{array}{c}\text { Final } \\
\text { Approval Votes }\end{array}$} \\
\hline & & & $\bar{A}$ & B & C & $\bar{A}$ & $B$ & C & & $A$ & $B$ & C & $\bar{A}$ & B & C & $A$ & B & C \\
\hline 1 & 4 & 5 & 1500 & 2000 & 600 & 250 & 1000 & 300 & Yes & 37 & 49 & 15 & 3170 & 5560 & 2307 & Yes & Yes & Yes \\
\hline 2 & $\overline{4}$ & 4 & 450 & 2500 & 766 & 250 & 800 & 300 & Equal & $\overline{12}$ & 67 & 21 & 4002 & 4932 & 2104 & $\overline{\text { Yes }}$ & No & No \\
\hline 3 & $\overline{2}$ & 3 & 350 & 1200 & 701 & 400 & 250 & 150 & Yes & $\overline{16}$ & 53 & 31 & 3306 & 5024 & 1864 & $\overline{\text { Yes }}$ & No & No \\
\hline 4 & 2 & 3 & 250 & 1300 & 724 & 400 & 300 & 150 & Yes & 11 & 57 & 32 & 3406 & 4939 & 1849 & Yes & No & No \\
\hline 5 & 0 & 1 & 150 & 750 & 725 & 850 & 1300 & 0 & Yes & 9 & 46 & 45 & 2000 & 4000 & 2000 & No & No & No \\
\hline 6 & 5 & 4 & 1500 & 3500 & 0 & 200 & 675 & 150 & No & 30 & 70 & 0 & 3263 & 4259 & 2896 & Yes & No & Yes \\
\hline 7 & $\overline{4}$ & 5 & 550 & 4000 & 100 & 250 & 1075 & 100 & Yes & 12 & 86 & $\overline{2}$ & 4012 & 4294 & 2732 & $\overline{Y e s}$ & No & Yes \\
\hline 8 & 0 & 0 & 350 & 1050 & 200 & 1000 & 1050 & 0 & Equal & 22 & 66 & 13 & 2000 & 4000 & 2000 & No & No & No \\
\hline 9 & 3 & 4 & 1500 & 1400 & 200 & 300 & 600 & 300 & Yes & 49 & 45 & 6 & 2821 & 5599 & 2525 & $\overline{\mathrm{No}}$ & Yes & Yes \\
\hline 10 & 3 & 4 & 550 & 2200 & 425 & 300 & 500 & 250 & Yes & 17 & 69 & 13 & 3629 & 4971 & 2345 & Yes & Yes & Yes \\
\hline 11 & 3 & 4 & 500 & 2000 & 560 & 300 & 550 & 250 & Yes & 16 & 65 & 18 & 3654 & 5074 & 2217 & Yes & Yes & Yes \\
\hline & & & & & & & & & & & & $\begin{array}{l}\text { non- } \\
\text { coop. }\end{array}$ & 2000 & 4173 & 2000 & & & \\
\hline
\end{tabular}


Table 6. Example of Smith-like Process, Game 1, Optimal $Q=8$, Provision Point Test at Group Average

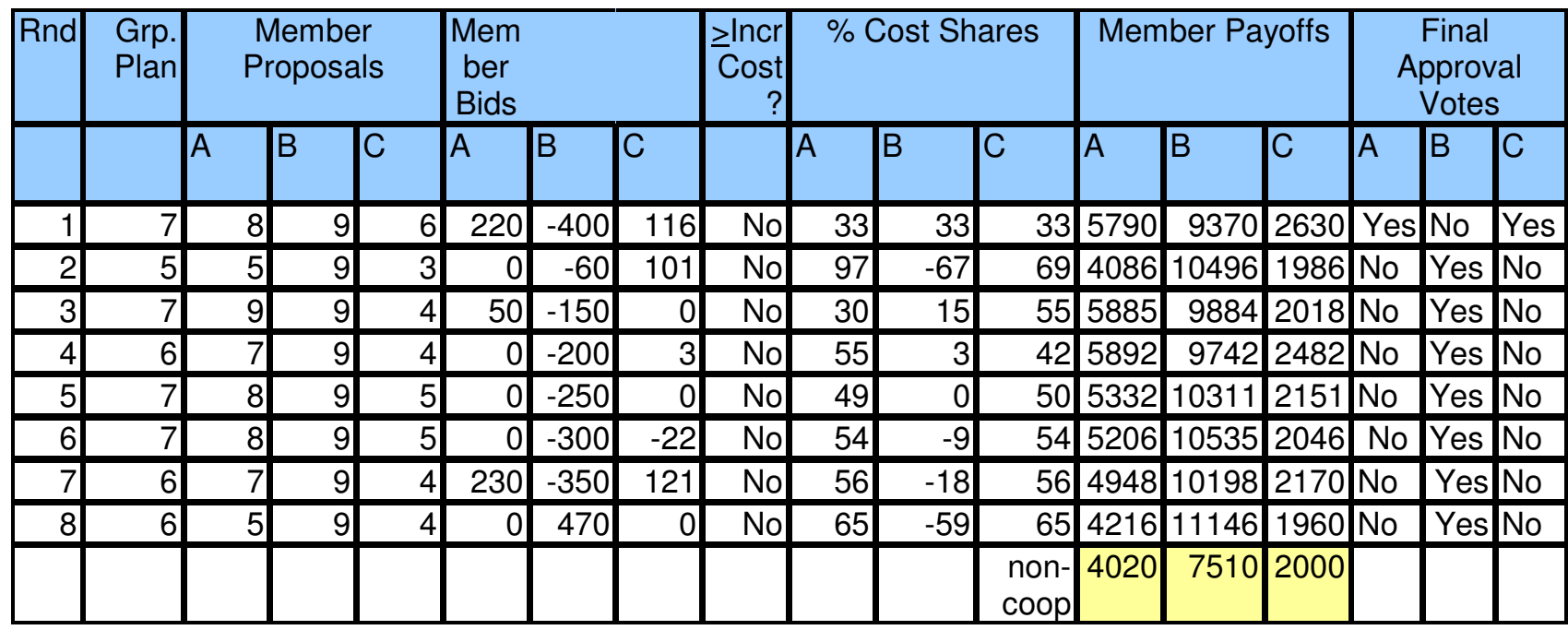


Table 7. Experimental Comparison of Alternative Cost Share Adjustment Processes

$\begin{array}{lllll} & \text { Game } & & & \\ & \mathbf{1} & \mathbf{2} & \mathbf{3} & \text { Overall } \\ \text { Efficient } \mathrm{Q} & 8 & 7 & 4 & \end{array}$

Quantity Process

\begin{tabular}{|c|c|c|c|c|c|}
\hline \%Efficiency & 0.83 & 1.0 & 1.0 & 0.94 & \\
\hline Avg. \# Rounds & 3.33 & 5.0 & 5.05 & 4.44 & \\
\hline \# Games & 3 & 3 & 3 & 9 & \\
\hline \# No Agreement & & & & $0 / 9$ & $=0.0$ \\
\hline \multicolumn{6}{|l|}{ Bid/Quantity Process } \\
\hline \%Efficiency & 0.50 & 0.80 & 0.65 & 0.65 & \\
\hline Avg. \# Rounds & 5.40 & 5.00 & 6.40 & 5.4 & \\
\hline \# Games & 5 & 5 & 5 & 15 & \\
\hline $\begin{array}{l}\text { \# Rounds Provision Met } \\
\text { \# Neqative or Zero Bids }\end{array}$ & & & & $\begin{array}{l}39 / 84 \\
63 /(3 \times 84)\end{array}$ & $\begin{array}{l}=0.46 \\
=0.25\end{array}$ \\
\hline \# No Agreement & & & & $\begin{array}{l}03 /(3 \times 04) \\
2 / 15\end{array}$ & $\begin{array}{l}=0.25 \\
=0.13\end{array}$ \\
\hline
\end{tabular}

$\underline{\text { Smith-like Process }}$

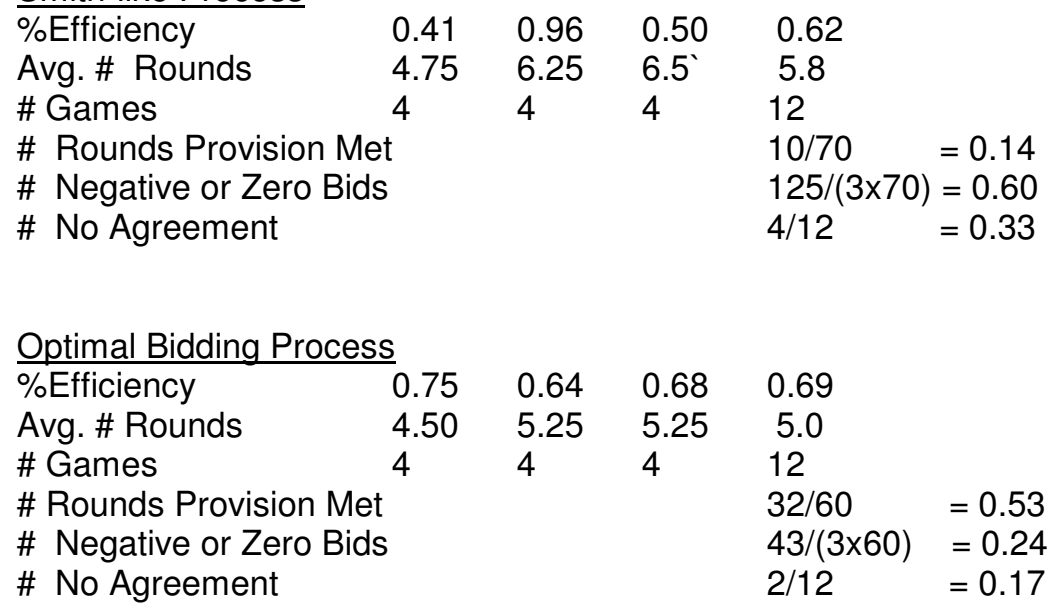


Table 8. More Trials of the Quantity Process

\begin{tabular}{|l|l|l|l|l|}
\hline Game & 1 & 2 & 3 & Overall \\
\hline Efficient Q & 7 & 4 & 8 & \\
\hline \# Games & 48 & 48 & 48 & 144 \\
\hline Percent Efficiency & 0.77 & $0.71^{*}$ & 0.83 & 0.77 \\
\hline $\begin{array}{l}\text { Avg. \# } \\
\text { Proposal Rounds }\end{array}$ & $3.60^{* *}$ & 4.79 & 4.79 & 4.39 \\
\hline $\begin{array}{l}\text { Equal Shares } \\
\text { Approved, \% }\end{array}$ & $0.50^{* *}$ & $0.14^{*}$ & 0.29 & 0.31 \\
\hline $\begin{array}{l}\text { QU Found } \\
\text { QU Approved }\end{array}$ & $0.29^{* *}$ & 0.54 & 0.56 & 0.46 \\
\hline $\begin{array}{l}\text { Conditional Prob. } \\
\text { Accept QU }\end{array}$ & $0.34^{* *}$ & $0.57^{* *}$ & 0.36 & 0.46 \\
\hline
\end{tabular}

QU denotes Quantity Unanimity for the shared good

* Significant difference between adjacent pairs, 95\% t-test

${ }^{* *}$ Significant difference between adjacent pairs, 99\% t-test 


\section{References}

Andreoni, James, [1988], Why Free Ride? Strategies and Learning in Public Goods Experiments, Journal of Public Economics 37, 291-304.

Arrow, Kenneth J., and Leonid Hurwicz [1960], Decentralization and Computation in Resource Allocation Processes, in K.J. Arrow, S. Karlin, P. Suppes (eds.), Mathematical Methods in the S ocial Sciences, Stanford University Press, Palo Alto, CA.

Atkins, D. [1974], Managerial Decentralization and Decomposition in Mathematical Programming, Operational Research Quarterly 25(4), pp.615-624.

Bagnoli, Mark and Michael McKee [1991], Voluntary Contribution Games: Efficient Private Provision of Public Goods: the Multiple Unit Case, Economic Inquiry 29, 351-366.

Bagnoli, Mark, Shaul Ben-David, and Michael McKee [1992], Voluntary Provision of Public Goods, Journal of Public Economics 47, 85-106.

Bagnoli, Mark and Barton L. Lipman [1989], Provision of Public Goods: Fully Implementing the Core Through Private Contributions, Review of Economic Studies 56, 583-601.

Bagnoli, M., S. Ben-David, and M. McKee [1992], Voluntary Provision of Public Goods, Journal of Public Economics 47, 85-106.

Banks, J.S., C.R. Plott, D.P. Porter [1988], An Experimental Analysis of Unanimity in Public Goods Provision Mechanisms, Review of Economic Studies 40, 301-322.

Bergstrom, Theodore, Blume, Lawrence, and Hal Varian [1986], On the Private Provision of Public Goods, J. of Public Economics 29, 25-49.

Blumel, Wolfgang, Pethig Rudiger, and Oskar von dem Hagen [1986], The Theory of Public Goods: a Survey of Recent Issues, Journal of Institutional and Theoretical Economics 142 (2), 241309.

Biro, Miklos, and Laszlo Kovacs [1994], Protocols for Cooperative Multiple Criteria Decision Processes. Computer and Automation Institute of the Hungarian Academy of Sciences, Informatics Research Laboratory. http://dsd.sztaki.hu/publications/protocolgdss/protocolGDSS.pdf

Bui, Tun X. [1987], Co-oP, A Group Decision Support System for Cooperative multiple Criteria Group Decision Making, Lecture Notes in Computer Science, Springer-Verlag.

Chan, Kenneth S., Stuart Mestelman, Rob Moir, and R. Andrew Muller [1999], Heterogeneity and the Voluntary Provision of Public Goods, Experimental Economics 2, 5-30. 
Chan, Kenneth S., Stuart Mestelman, Rob Moir, and R. Andrew Muller [1996], The Voluntary Provision of Public Goods under Varying Income Distribution, Canadian Journal of Economics 29, 54-69.

Chander, Parkash [1993], Dynamic Procedures and Incentives in Public Good Economies, Econometrica 61(6), 1341-1354.

Chanron, Vincent and Kemper Lewis [2005], A Study of Convergence in Decentralized Design, Research in Engineering Design 116(3), pp. 133-145.

Chen, Yan [2008], Incentive-compatible Mechanisms for Pure Public Goods: A Survey of Experimental Research, in Handbook of Experimental Economics Results, Vol. 1, Chapter 67, Elsevier B.V.

Chen, Yan and Charles R. Plott [1996], The Groves-Ledyard Mechanism: an Experimental Study of Institutional Design, Journal of Public Economics 59, 335-364.

Coates, Jennifer C. and Gronberg, Timothy J. [1996], Provision of Discrete Public Goods: An Experimental Investigation of Alternative Institutions. Manuscript, TAMU Economics Laboratory, Texas A\&M University.

Cohen, Susan I. [1986], Truth-telling, Dominant Strategies, and Iterative Groves Mechanisms, Public Choice 51 (3), pp. 333-343.

Cohen, Susan I. [1980], Incentives, Iterative Communication, and Organizational Control, Journal of Economic Theory 22, pp.37-55.

Cornes, Richard and Todd Sandler [1996], The Theory of Externality, Public Goods, and Club Goods, Cambridge University Press.

Dasgupta, D. [1997], Voluntary Contribution to Public Goods: A Parable of Bad Samaritans, in Issues in Economic Theory and Public Policy, eds. A. Bose, M. Rakshit, A. Sinha, Oxford University Press, Calcutta.

Dougherty, Keith [2003], Public Goods Theory from Eighteenth Century Political Philosophy to Twentieth Century Economics, Public Choice 117, 239-253.

Dreze, J.H. and D. de la Vallee Poussin [1971], A Tatonnement Process for Public Goods, Review of Economic Studies 38, 133-150.

Foldvary, Fred [1994], Public Goods and Private Communities. Edward Elgar Press.

Gardner, Roy, Andrew Herr, Elinor Ostrom and James M. Walker, [2000], Collective Choice in the Commons: Experimental Results on Proposed Allocation Rules and Votes, The Economic Journal $110(460), 212-234$. 
Groves, Theodore, and John O. Ledyard [1977a], Optimal Allocation of Public Goods: a Solution to the Free Rider Problem, Econometrica 45, 783-809.

Groves, Theodore, and John O. Ledyard [1977b], Some Limitations of Demand Revealing Processes, Public Choice 29, 107-124.

Hart, Jeffrey, Peter F. Cowley [1977], Theories of Collective Goods Reexamined, The Western Political Quarterly 30(3), 351-362.

Head, J. [1962], Public Goods and Public Policy, Public Finance 27, 197-219.

Hurwicz, Leonid and Stanley Reiter [2006]. Designing Economic Mechanisms, Cambridge University Press.

Hurwicz, L. [1994], Economic Design, Adjustment Processes, Mechanisms, and Institutions, Economic Design 1, 1-14.

Hurwicz, L. [1987], Inventing New Institutions: The Design perspective, American J. of Agricultural Economics 69

Hurwicz, L [1973], The Design of Mechanisms for Resource Allocation, American Economic Review 63, 1-30.

Hurwicz, L. [1972], On Informationally Decentralized Systems, in C.B. McGuire and Roy Radner, eds., Decision and Organization, $2^{\text {nd }}$ ed., University of Minnesota Press, 297-336.

Hurwicz, L. [1971], Centralization and Decentralization in Economics Processes, in A. Eckstein (ed.), Comparison of Economic Systems: Theoretical and Methodological Approaches, University of California Press, Berkeley.

Isaac, R. M. and J. M. Walker [1988a], Communications and Low-proposing Behavior: The Voluntary Contribution Mechanism, Economic Inquiry 24, 585-608.

Isaac, R. M. D. Schmitz, and J. M. Walker [1989], The Assurance Problem in a Laboratory Market, Public Choice 62, 217-36.

Isaac, R. Mark, James M. Walker, and Susan H. Thomas [1984], Divergent Evidence on Free Riding: An Experimental Examination of Possible Explanations, Public Choice 43, 113- 149.

Isaac, R. Mark, Kenneth F. McCue, and Charles R. Plott [1985], Public Goods Provision in an Experimental Environment, Journal of Public Economics 26, 51-74.

Kaneko, M. [1977], The Ratio Equilibrium and a Voting Game in a Public Goods Economy, Journal of Economic Theory 16, 123-136. 
Ledyard, John O. [1995], Public Goods: A Survey of Experimental Research, in the Handbook of Experimental Economics, ed. A. Roth and J. Kagel.

Li, Shu-Chu Sarrina, [2007], Computer-mediated Communication and Group Decision Making: a

Functional Perspective, Small Group Research 38(5), 593-614. Doi: 10.1177/1046496407304335

Lindahl, E. [1919], Just Taxation - a Positive Solution, in R. Musgrave and A. Peacock, eds., Classics in the Theory of Public Finance, 1958, p. 68-176, St. Martin's Press, New York. Harstad, R. M. and M. Marrese, 1982. Behavioral Explanation of Efficient Public Good Allocations, Journal of Public Economics 19, 367-383.

Laub, A.J., and F.N. Bailey [1978], An Iterative Coordination Approach to Decentralized Decision Problems, Automatic Control, IEEE Transactions (December).

Loehman, Edna and Andrew Whinston [1971], A New Theory or Pricing and Decision-making for Public Investment, The Bell Journal of Economics and Management Science 2(2), pp. 606-625.

Marshall, Alfred, 1890. Principles of Economics.

Mas-Colell, Andreu [1980], Efficiency and Decentralization in the Pure Theory of Public Goods. Quarterly Journal of Economics XCIV (4).

Mas-Colell, Andreu and Joaquim Silvestre [1989], Cost Share Equilibria: Lindahlian Approach, Journal of Economic Theory 47, 239-256.

Mas-Colell, Andreu and Joaquim Silvestre [1991], A Note on Cost-Share Equilibrium and OwnerConsumers, Journal of Economic Theory 54, 204-214.

Mookherjee, Dilip [2008], The 2007 Nobel Memorial Prize in Mechanism Design Theory, Scandanavian J. of Economics 110, 237-260.

Mount, Kenneth and Stanley Reiter [1974], The Informational Size of Message Spaces, Journal of Economic Theory 8, 161-192.

Musgrave, R.A. [1939], The Voluntary Exchange Theory of Public Economy, Quarterly Journal of Economics 53, 213-237.

Musgrave, R. A [1959], The Theory of Public Finance, McGraw-Hill, New York.

Olson, Mancur [1970], The Logic of Collective Action, Harvard University Press, Cambridge, Mass.

Pickhardt, Michael [2006], Fifty Yeaers after Samuelson’s “The Pure Theory of Public

Expenditure": What are we left with, Journal of the History of Economic Thought 28(4), 439-460. 
Nisan, Noam and Amir Ronen [2001], Algorithmic Mechanism Design, Games and Economic Behavior 35: 166-196.

Ostrom, E., R. Gardner, and J. Walker [1994], Rules, Games, and Common Pool Resources, Univ. of Michigan Press, Ann Arbor.

Reiter, Stanley [1995], Coordination and the Structure of Firms, Discussion Paper \#1121, Northwestern University, Center for Mathematical Studies in Economics and Management Science, www.kellogg.northwestern.edu/research/math/papers/1121.pdf, accessed Oct. 25, 2011.

Reiter, Stanley [1974], Information Efficiency of Iterative Processes and the Size Message Spaces, Journal of Economic Theory 8, 193 -205.

Roberts, Donald John, [1974], The Lindahl Solution for Economies with Public Goods, Journal of Public Economics 3, 23-42.

Samuelson, Paul, 1955. Diagrammatic Exposition of a Theory of Public Expenditures, Review of Economics and Statistics 40, 332-338.

Samuelson, Paul A [1954], The Pure Theory of Public Expenditures, Review of Economics and Statistics 36, 87-389.

Sell, Jane and Rick K. Wilson [1991], Levels of Information and Contributions to Public Goods, Social Forces 70, 107-124.

Silvestre, Joaquim, [2003], Wicksell, Lindahl, and the Theory of Public Goods, Scandinavian Journal of Economics 105(4), 627-553.

Smith, Vernon L. [1989], Theory, Experiment, and Economics, Journal of Economic Perspectives, Winter, 151-169.

Smith, Vernon L. [1980], Experiments with a Decentralized Mechanism for Public Good Decisions, American Econ. Review 70, 584-599.

Smith, Vernon L [1980], Relevance of Laboratory Experiments to Testing Resource Allocation Theory, in Evaluation of Econometric Models, edited by J. Kmenta and J. Ramsey, New York Academic Press, 345-77.

Smith, Vernon. L. [1979], An Experimental Comparison of Three Public Good Decision Mechanisms, Scandanavian Journal of Economics 81 (2), 198-215.

Smith, Vernon L [1978], Incentive Compatible Experimental Processes for the Provision of Public Goods, in Vernon L. Smith, ed., Research in Experimental Economics, vol. 1, JAI Press.

Smith, V.L. [1977], The Principle of Unanimity and Voluntary Consent in Social Choice, Journal of Political Economics, 1125-1139. 
Smith, Vernon L [1976], Experimental Economics: Induced Value Theory, American Economics Review, May, 274-79.

Takayama, Akira [1985], Mathematical Economics, Cambridge University Press, Cambridge.

Tideman, Nicholas [1998], The Ethics of Coercion in Public Finance, in alexander Pozdnyakov (ed.) Order and Chaos in the Development of Socio-Economic Systems, p. 16-25, The Institute of Optimal Monitoring, Tomsk.

Tiebout, Charles [1956], A Pure Theory of Local Expenditures, J. of Political Economy 64(5), 416424.

Tulkens, H. [1978], Dynamic Processes for Public Goods, Journal of Public Economics 9, 163201.

Weber, Shlomo and Hans Wiesmeth [1991], The Equivalence of Core and Cost Share Equilibria in an Economy with a Public Good, Journal of Economic Theory 54, 180-197.

Wicksell, Knut [1896], A New Principle of Just Taxation, in R.A. Musgrave and A.T. Peacock, eds, Classics in Theory of Public Finance, pp.72-118, Macmillan and Co, London, UK.

Wong, K. P. [1973], The Efficiency of Decomposition vs. Direct Solution with Implications for the Question of Decentralized or Centralized Planning, Economics of Planning 13(3), pp. 199-209.

Young, H. Peyton, ed. [1985], Cost Allocation, Elsevier Science.

Young, H. Peyton [1994], Equity: In Theory and Practice, Princeton University Press.

Ziss, S. [1996], Public Good Provision and the Smith Process, Economic Design 2, 245-261. 


\section{Appendix 1: Rule Descriptions}

In the instructions for each institution, each was described in terms of its general properties (computational details were a "black box."). For share-taking processes, the initial cost allocation schedule with equal shares was first shown. After each subject makes quantity and/or bid proposals, a new cost allocation schedule is displayed on the next round, with corresponding net payoffs.

Share-taking processes with price adjustment had a similar information format: cost allocation, benefit, and net reward schedules were presented for a schedule of ten quantity levels. After seeing the information screen, each subject responded with a message about the desired shared good quantity. Summaries of proposals and resulting shares of cost for all group members by round were available as public information on history and voting screens.

Instructions for the Proposal Phase were as follows, by process:

Quantity Process. "The computer will determine the group plan based on the average of members' quantity proposals. Overall, a larger quantity means that both benefits and cost shares will increase for all group members.

Cost shares are equal in the first round. Your cost share for subsequent rounds will be calculated by the computer based on your quantity proposals relative to others' proposals. If your quantity proposal is greater than the average proposal, your cost share will increase on the next round. Conversely, your cost share will decrease if your proposal is less than the average."

Bid/Quantity Process. "The computer will determine the group plan based on the average of members' quantity proposals. Overall, a larger quantity means that both benefits and cost shares will increase for all group members.

Each round, the group plan begins at the average of group members' quantity proposals minus one. Given the newly calculated group plan, you will be asked to bid to increase the group plan to the next higher level. To make the increase to the next higher level, the total of bids must be enough to cover the extra cost for that plan. Cost shares are equal on the first round. Your cost share for subsequent rounds will be calculated by the computer based on your bids relative to others' bids. If your bid is greater than the average, your cost share will increase on the next round. Conversely, your cost share will decrease on the next round if your bid is less than the average."

Smith-like Process. "The computer will determine the group plan based on the average of members' quantity proposals. Overall, a larger quantity means that both benefits and cost shares will increase for all group members.

Given the newly calculated group plan, you will be asked to propose your bid to increase the group plan to the next higher level. To make the increase, the total of bids proposed by the group must be enough to cover the increased cost for that plan.

Cost shares are equal in the first round. Your cost share for subsequent rounds will be calculated by the computer. If your bid is greater than the average bid, your cost share will increase. Conversely, if 
your bid is less than the average, your cost share will decrease. You can also receive a bonus - a reduced cost share - if your quantity proposal is greater than the average quantity proposal. Conversely, a quantity proposal less than the average can mean a penalty in terms of increasing your share."

Optimal Bidding Process. Although the overall form of this game followed the proposal and approval phase format, the information format is different from the other cost share adjustment processes. A matrix displays the quantities that different levels of contributions could "buy", in terms of the individual's own bid and the sum of others' bids. As for VCM, another matrix shows corresponding net rewards by own bid and sum of others' bids.

The rules of the process were described as follows. "Each round you will:

1) Make a Bid, to determine a feasible commodity plan and cost shares.

The sum of your bid and others' bids will result in a Feasible Group Plan. The computer will determine this plan from the highest level that can be afforded given the total bids and the cost for each plan level.

Your cost share will never be more than your bid on any round.

Since the sum of bids may be greater than the required cost for the feasible plan, bids are adjusted so that excess revenue is not collected. The percent share of group cost that you will pay is the relative proportion of your bid to the sum of bids.

Your net reward for each round will be based on the feasible commodity plan and your cost share.

2) Make an Incremental Bid, to suggest a new plan and cost share for the next round Your benefit would increase if the group plan level were to increase. Your Incremental Bid represents an extra contribution over your current cost share toward an increase in the plan level.

The Suggested Group Plan is determined by the computer in the direction of maximal group net returns.

- If the sum of incremental bids exceeds the extra cost to increase the plan, then the Suggested Group Plan is one level higher than the current feasible plan.

- If the sum of incremental bids is less than required, then the Suggested Group Plan is one level less than the current feasible plan.

- If the sum of incremental bids exactly equals the extra cost, the Suggested Group plan is the same as the current feasible plan.

Your Suggested Cost Share for the next round will be in proportion to the sum of your original cost share and your incremental bid, if the plan level increases. The suggested cost shares will exactly cover the cost of the Suggested Group Plan." 


\section{Appendix 2: Details of Simulation of CSAPs}

Utility functions: $u_{i}=\log \left(1+\mathrm{x}_{\mathrm{i}}\right)+\gamma_{\mathrm{i}} \log (1+\mathrm{Q})$.

Preference parameters: $\gamma_{1}=1, \gamma_{2}=2, \gamma_{3}=1$.

Endowments: $\mathrm{M}_{1}=20, M_{2}=10, M_{3}=10$.

Cost function: $C(Q)=10+10 Q-5 Q^{2}+5 Q^{3}$ for $Q>0$;

$$
C(0) \equiv 0 \text {. }
$$

The base for utility changes is $Q=0$ and $x_{i}=M_{i}$.

Theoretical Linear Cost Share Equilibrium, $\mathrm{s}_{\mathrm{i}}=1 / \mathrm{n}$ :

$\begin{array}{lll}Q & = & .964 \\ \mathrm{p}_{1} & = & 1.80 \\ \mathrm{p}_{2} & = & -.03 \\ \mathrm{p}_{3} & = & -1.77\end{array}$

$\Delta \mathrm{u}_{1}=.18 ; \Delta \mathrm{u}_{2}=.48 ; \Delta \mathrm{u}_{3}=.08$.

Theoretical Ratio Equilibrium:

$\begin{array}{lll}Q & = & .965 \\ \mathrm{~s}_{1} & = & .441 \\ \mathrm{~s}_{2} & = & .328 \\ \mathrm{~s}_{3} & = & .231\end{array}$

$\Delta \mathrm{u}_{1}=.15 ; \Delta \mathrm{u}_{2}=.48 ; \Delta \mathrm{u}_{3}=.15$

Quantity Process, $\mathrm{s}_{\mathrm{i}}=1 / \mathrm{n}$ :

Converged after 23 iterations.

$\Delta u_{1}=.18 ; \Delta u_{2}=.48 ; \Delta u_{3}=.08$

\begin{tabular}{|c|c|c|c|c|c|}
\multicolumn{1}{l}{$\underline{\underline{3}} \underline{\underline{3}}$} & $\underline{1}$ & $\underline{6}$ & $\underline{11}$ \\
\hline$\overline{\mathrm{Q}}$ & .93 & .95 & .957 & .963 & .964 \\
\hline $\mathrm{Q}_{1}$ & 1.163 & 1.09 & 1.03 & .983 & .965 \\
\hline $\mathrm{Q}_{2}$ & .95 & .95 & .95 & .958 & .964 \\
\hline $\mathrm{Q}_{3}$ & .68 & .81 & .90 & .947 & .964 \\
\hline $\mathrm{p}_{1}$ & .39 & .92 & 1.35 & 1.68 & 1.80 \\
\hline $\mathrm{p}_{2}$ & .04 & .04 & .003 & .003 & -.03 \\
\hline $\mathrm{p}_{3}$ & -.42 & -.96 & -1.35 & -1.68 & -1.77 \\
\hline
\end{tabular}


Groves-Ledyard Personalized Price Process, $\mathbf{s}_{\mathbf{i}}=\mathbf{1} / \mathbf{n}$

Penalty Parameter $\gamma=5$ :

Disagreement equilibrium after seven iterations.

$\Delta u_{1}=.29 ; \Delta u_{2}=.53 ; \Delta u_{3}=-.27$.

\begin{tabular}{|c|c|c|c|c|c|}
\multicolumn{1}{|c}{ Iteration } & \multicolumn{1}{c}{$\underline{\underline{3}}$} & \multicolumn{1}{c}{$\underline{\underline{6}}$} & $\underline{7}$ \\
\hline \hline$\overline{\mathrm{Q}}$ & .930 & .926 & .925 & .925 & .925 \\
\hline $\mathrm{Q}_{1}$ & 1.16 & 1.16 & 1.16 & 1.162 & 1.162 \\
\hline $\mathrm{Q}_{2}$ & .95 & 1.00 & 1.006 & 1.009 & 1.009 \\
\hline$Q_{3}$ & .68 & .62 & .613 & .607 & .606 \\
\hline $\mathrm{p}_{1}$ & .12 & .025 & .012 & .008 & .007 \\
\hline $\mathrm{p}_{2}$ & -.31 & -.371 & -.38 & -.388 & -.390 \\
\hline $\mathrm{p}_{3}$ & .19 & .346 & .37 & .381 & .383 \\
\hline
\end{tabular}

Similarly, for penalty parameters $\gamma=3$ and $\gamma=10$, disagreement equilia occurred.

Bid/Quantity Process, $\mathrm{s}_{\mathrm{i}}=1 / \mathrm{n}$ :

Converged after 5 iterations.

$\Delta u_{1}=.18 ; \Delta u_{2}=.48 ; \Delta u_{3}=.08$

\begin{tabular}{|c|c|c|c|c|c|}
\hline Iteration & $\underline{1}$ & $\underline{2}$ & $\underline{3}$ & 4 & $\underline{5}$ \\
\hline$\overline{\mathrm{Q}}$ & .927 & .96 & .964 & .965 & .965 \\
\hline $\mathrm{Q}_{1}$ & 1.17 & 1.00 & .971 & .966 & .965 \\
\hline $\mathrm{Q}_{2}$ & .96 & .96 & .962 & .964 & .964 \\
\hline $\mathrm{Q}_{3}$ & .66 & .92 & .958 & .964 & .965 \\
\hline $\mathrm{p}_{1}$ & 1.49 & 1.75 & 1.7 & 1.80 & 1.80 \\
\hline $\mathrm{p}_{2}$ & -.02 & -.02 & -.03 & -.03 & -.03 \\
\hline $\mathrm{p}_{3}$ & -1.47 & -1.73 & -1.76 & -1.76 & -1.77 \\
\hline
\end{tabular}




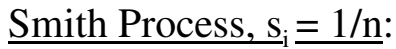

Converged in seven iterations.

$\Delta u_{1}=.18 ; \Delta u_{2}=.48 ; \Delta u_{3}=.09$

\begin{tabular}{|c|c|c|c|c|c|}
\multicolumn{1}{|c}{ Iteration } & \multicolumn{1}{c}{$\underline{\underline{2}}$} & \multicolumn{1}{c}{$\underline{\underline{6}}$} & $\underline{7}$ \\
\hline \hline$\overline{\mathrm{Q}}$ & .93 & .955 & .964 & .965 & .966 \\
\hline $\mathrm{Q}_{1}$ & 1.16 & 1.03 & .98 & .967 & .966 \\
\hline $\mathrm{Q}_{2}$ & .95 & .98 & .96 & .965 & .966 \\
\hline $\mathrm{Q}_{3}$ & .68 & .86 & .95 & .965 & .966 \\
\hline $\mathrm{p}_{1}$ & 1.18 & 1.54 & 1.72 & 1.74 & 1.75 \\
\hline $\mathrm{p}_{2}$ & -.19 & -.11 & -.09 & -.09 & -.09 \\
\hline $\mathrm{p}_{3}$ & -.99 & -1.43 & -1.64 & -1.66 & -1.66 \\
\hline
\end{tabular}

\section{MDP Planning Process:}

Speed of adjustment $\gamma=0.05$.

Initial taxes $=3.4$ each to cover fixed cost of 10 .

Converges to a stationery point in six iterations that is not optimal.

Cumulative taxes sum to slightly more than cost.

$\Delta u_{1}=.13 ; \Delta u_{2}=.44 ; \Delta u_{3}=.08$.

\begin{tabular}{|l|l|l|l|l|l|}
\multicolumn{1}{l}{ Iteration } & \multicolumn{1}{l}{$\underline{\underline{2}} \underline{\underline{4}}$} & $\underline{6}$ \\
\hline $\mathrm{Q}$ & .49 & .65 & .73 & .74 & .741 \\
\hline $\operatorname{Tax}_{1}$ & 6.07 & 6.87 & 7.27 & 7.31 & 7.32 \\
\hline $\operatorname{Tax}_{2}$ & 4.57 & 5.07 & 5.33 & 5.36 & 5.37 \\
\hline $\operatorname{Tax}_{3}$ & 3.64 & 3.95 & 4.13 & 4.15 & 4.15 \\
\hline $\begin{array}{l}\mathrm{Tax} \\
\text { Sum }\end{array}$ & 14.28 & 15.89 & 16.73 & 16.82 & 16.84 \\
\hline Cost & 14.25 & 15.75 & 16.57 & 16.66 & 16.71 \\
\hline
\end{tabular}

The process leads to individually infeasible quantity changes for penalty parameters $\gamma=1.0,0.5,0.25,0.15$, and 0.1 
Optimal Bid Process:

Speed of adjustment $\gamma=0.05$.

Initial bids based on equal shares for $\mathrm{Q}=1$ at cost of $\$ 20$.

Converges to optimum in eighteen iterations.

$\Delta u_{1}=.15 ; \Delta u_{2}=.48 ; \Delta u_{3}=.15$.

\begin{tabular}{|c|c|c|c|c|c|}
\hline Iteration & 1 & $\underline{5}$ & $\underline{10}$ & 15 & 18 \\
\hline $\mathrm{Q}$ & 1.0 & .952 & .97 & .963 & .965 \\
\hline $\mathrm{s}_{1}$ & .33 & .43 & .44 & .44 & .44 \\
\hline $\mathrm{s}_{2}$ & .33 & .33 & .33 & .33 & .33 \\
\hline $\mathrm{S}_{3}$ & .33 & .24 & .23 & .23 & .23 \\
\hline
\end{tabular}

Note: the process starts out at equal shares with negative utility for person three for the first round. 